This item was submitted to Loughborough's Research Repository by the author.

Items in Figshare are protected by copyright, with all rights reserved, unless otherwise indicated.

\title{
A new individualized thermoregulatory bio-heat model for evaluating the effects of personal characteristics on human body thermal response
}

PLEASE CITE THE PUBLISHED VERSION

https://doi.org/10.1016/j.buildenv.2018.03.026

\section{PUBLISHER}

(C) Elsevier

VERSION

AM (Accepted Manuscript)

\section{PUBLISHER STATEMENT}

This work is made available according to the conditions of the Creative Commons Attribution-NonCommercialNoDerivatives 4.0 International (CC BY-NC-ND 4.0) licence. Full details of this licence are available at: https://creativecommons.org/licenses/by-nc-nd/4.0/

\section{LICENCE}

CC BY-NC-ND 4.0

\section{REPOSITORY RECORD}

Davoodi, Farzin, Hassan Hassanzadeh, Seyed A. Zolfaghari, George Havenith, and Mehdi Maerefat. 2019. "A New Individualized Thermoregulatory Bio-heat Model for Evaluating the Effects of Personal Characteristics on Human Body Thermal Response". figshare. https://hdl.handle.net/2134/32488. 


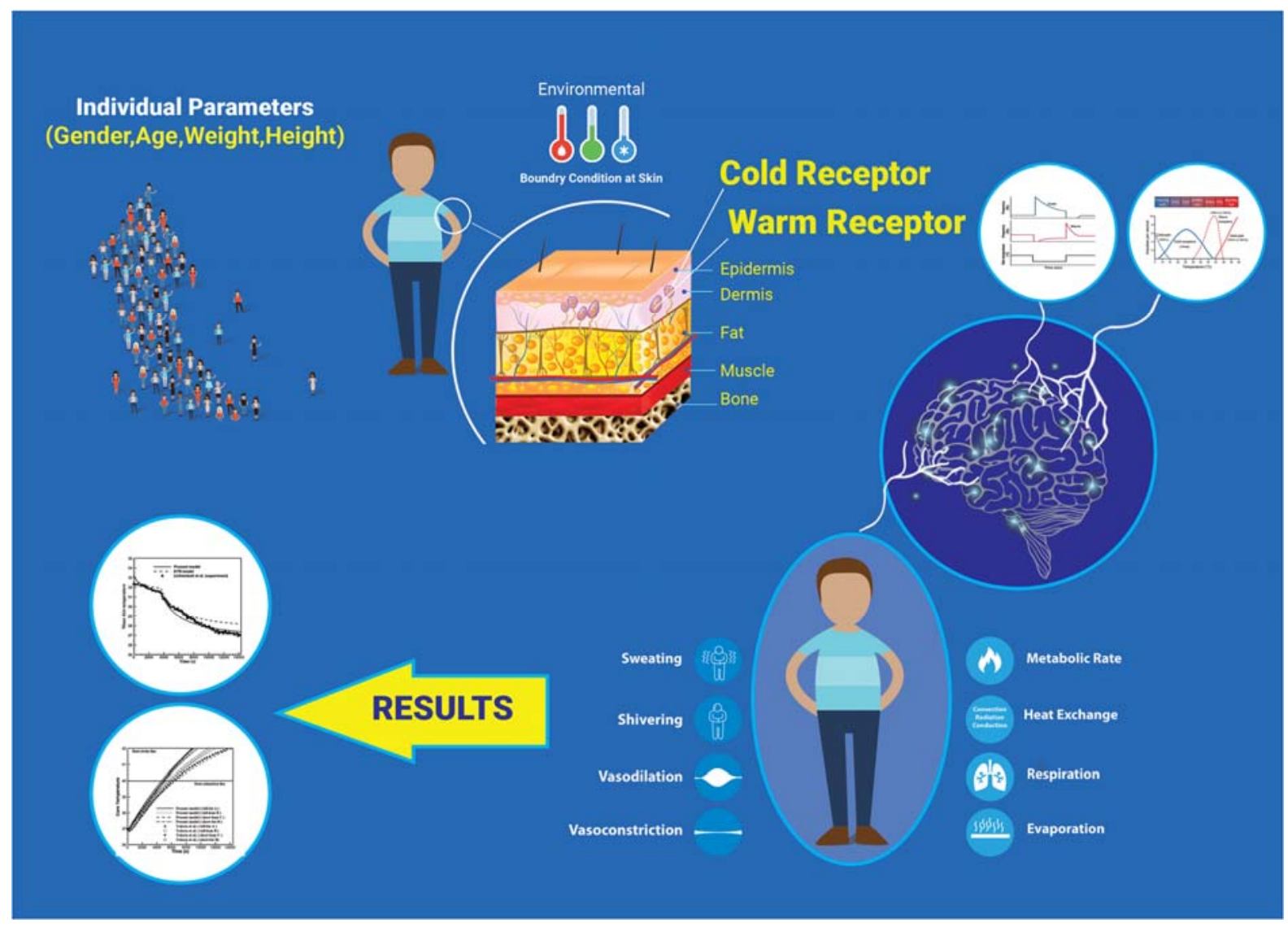

BAE-D-17-01947, "A new individualized thermoregulatory bio-heat model for evaluating the effects of personal characteristics on human body thermal response"

Farzin Davoodi, Hassan Hassanzadeh, Seyed Alireza Zolfaghari, George Havenith and Mehdi Maerefat).

Building and Environment, accepted 2018 

evaluating the effects of personal characteristics on human body

\section{thermal response}

Farzin Davoodia ${ }^{a}$, Hassan Hassanzadeh ${ }^{a}$, Seyed Alireza Zolfagharia,*, George Havenith ${ }^{\mathrm{b}}$,

Mehdi Maerefat ${ }^{\mathfrak{c}}$

${ }^{a}$ Department of Mechanical Engineering, University of Biriand, Birjand, Iran

${ }^{c}$ Department of Mechanical Engineering, Tarbiat Modares University, Tehran, Iran

Farzin Davoodi, Ph.D. candidate, E-mail: farzin_hi@yahoo.com, f.davoodi@,birjand.ac.ir 
3

\section{Abstract}

Personal factors such as weight, height, gender, age, and basal metabolic rate (BMR) all have significant effects on body temperature distribution and thermal sensation. A large number of wellknown human body thermoregulatory models are population-based however, and cannot evaluate the impact of individual characteristics on human thermal responses. Further, the standard thermal models of the human body, including Fanger's and Gagge's, are based on the energy balance approach. However, a person's thermal sensation is affected by the thermal response of cutaneous thermoreceptors relative to the environmental thermal conditions, and it is not necessarily related to the energy balance of the human body. Thus, these simplified standard models have some limitations under various individual conditions and are not in conformity with the physiology of individual thermoregulatory mechanisms. This study proposes a new Individualized Thermoregulatory Bio-heat (ITB) model on the basis of Pennes' equation and Gagge's 2-node model to determine heat transfer in living tissue layers. In developing this model, the effects of individual parameters such as age, gender, body mass index (BMI), and BMR on determining the temperature and its derivatives at cutaneous thermoreceptor locations were considered. Afterward, the present model was validated against the published empirical data, simulated standard model results, and analytical results under various environmental conditions and a good agreement was found.

Keywords: Bio-heat model, Individual parameters, STB model, Thermoreceptors, human body thermoregulation 


\section{Introduction}

Modeling the thermoregulatory systems of the human body and analyzing thermal comfort are complex processes, yet they attract a lot of research interest as they relate to numerous practical issues for researchers in physiological as well as in building comfort. Issues such as heterogeneous vascular layout, blood flow in the complex network of veins and arteries, metabolic heat production rate, and effects of individual physiological characteristics of human body tissues in thermal models are difficult to appraise. The combination of conduction, convection, radiation, and blood perfusion heat transfer methods in tissues are factors that increase this complexity [1]. There are many thermophysiological models to predict the mean skin temperature and thermoregulatory mechanisms of each body segment. But, these models do not directly evaluate the body thermal sensation and comfort. Therefore, thermal sensation and comfort models are used to translate thermophysiological and environmental information into perceived comfort sensation for people. Today, the accurate prediction of thermal comfort conditions is needed for a variety of applications, such as designing HVAC systems for buildings or personalized air conditioning in transport vehicles, for the textile and automotive industries, and for medical, aerospace, and military applications. To this end, over the years researchers have developed numerous human body heat balance and thermoregulatory models [2]. These models can be divided into two major groups: energy balance based models and combined energy balance-thermoregulation models. The Fanger's steady state [3] is the most well-known energy balance model that has been widely utilized for predicting thermal sensations in the common standards of thermal comfort $[4,5]$. Another example of such energy balance models is the required clothing Insulation Index (Ireq), looking at energy balance in the cold. Gagge's transient 2-node [6] model is probably the best example of a simple thermophysiological model used to assess thermal comfort, combining the external heat exchange energy model with a simple, two compartment passive body model as well as a physiological control model that regulates thermoregulatory responses based on input parameters like skin and core temperature (i.e. the temperature of the two compartments). Most examples listed below are based on the same principle but expand the complexity in different ways. Zolfaghari and Maerefat [7] also developed a simplified 3-node model (three lumped compartments: core, bare skin, and clothed skin) based on Gagge's model to evaluate critical thermal sensations. Moreover, several multi-segments models have been developed to provide more accurate predictions, especially for cold exposure, of the human body's thermal conditions. 
1 One of the most important and influential multi-segment models of the human body was developed by Stolwijk [8]. In this model, the body is divided into five cylindrical parts with four layers (central core, muscle, fat, skin). Based on this model principle, several other multi-segment models, including the Berkeley model [9], Tanabe model [10], ThermoSEM model [11], Kaynakli model [12], and Fiala model [13] were developed. A few of these models include some of individual differences like Berkeley model [9], Fiala model [14] and ThermoSEM[11] model, but they do not comprehensively cover all impacts of personal characteristics. It should be noted that despite their accuracy, using the mentioned models is considerably complex and serious limitations can arise in applying them. For example, determining the values of some input parameters in the mentioned models is not simple and easy-to-implement.

Individual characteristics can significantly affect the human body's thermoregulatory mechanisms. Differences in age, fitness, gender, body fat content, BMI, and BMR can significantly affect temperature distribution in body tissue and an individual's thermal sensations[15]. A large number of studies have purposed to determine relationships existing between individual characteristics, comfort and thermal responses: Havenith [16, 17] built on the Lotens [18] clothing model and the 2-node Gagge model, considering the impact of individual parameters (fitness, body mass, body fat content, acclimatization, sex and age) on the passive system and various control functions. Zhang et al. [19] proposed relationships for evaluating body fat, density, and BMR as functions of measurable parameters (height, weight, and gender). Van Marken Lichtenbelt et al. [20], Karjalainen et al. [21, 22], and Holopainen [23, 24] studied individual differences and their effects on human body thermoregulation and thermal comfort. Zhou et al. [25] reported that there are considerable differences in body size and composition between Chinese and Western adults, and they developed an individual native model to predict body temperature. Choi and Yeom [26] expressed that the conventional thermal sensation models have limitations in predicting individual thermal sensation levels, because they are not consider the effects of personal physiological characteristics. Results of their experimental study revealed that gender and BMI have a significant influence on the overall thermal sensation. Kim et al. [27] explored that personal comfort models based on occupants' heating and cooling behavior can estimate individual thermal preference and can provide more accurate representations of occupants' comfort needs. Also, Kim et al. [28], having reviewed existing thermal comfort models and their limitations, described that personal comfort models can benefit the building industry by improving the level of thermal comfort among 
occupants and optimizing energy consumption in building. Chaudhuri et al. [29] presented the predicted thermal state (PTS) model to determine the overall thermal state by considering two individual factors: body surface area and clothing insulation. Finally, the authors of the present study, Davoodi et al. [30], developed an individual 3-node body thermoregulatory model based on energy balance equations in which individual differences such as age, gender, BMI, and BMR were considered. This model can accurately estimate the thermal sensations of bare and clothed parts of the body with regard to individual characteristics in different environmental conditions.

Thermal sensation, however, is not necessarily related to the energy balance of the human body or to the average temperature of specific body compartments like core and skin. Actually, one's thermal sensation is affected by the thermal response of cutaneous thermoreceptors relative to environmental thermal conditions [31]. Therefore, energy balance-based models and models working with few and large compartments are not in conformity with the physiology of an individual's thermoregulatory system and are therefore not able to directly evaluate local thermal dissatisfaction (draught, asymmetric radiation, etc.). The thermal responses of warm and cold receptors depend on the temperature of the thermoreceptor and its time derivative [31]. In 1991, Ring and de Dear $[32,33]$ developed a human thermal response model based on static and dynamic thermal responses of cutaneous thermoreceptors. In a series of related studies in 2005 and 2007, Lv and Liu [34, 35] presented a new model based on the Ring and de Dear model [32] and its combination with a suitable bio-heat model. They used the well-known Pennes equation [36, 37] to compute the temperature distribution in the body tissue so as to evaluate the effect of transient temperature on thermoreceptors. In 2010, Zolfaghari and Maerefat [38] proposed a new simplified thermoregulatory bio-heat model (STB model). This model was a combination of the well-known Pennes' equation [36] and Gagge's 2-node model [6] and took into account thermoregulation mechanisms such as sweating, shivering, and vaso-motion. In 2011, Zolfaghari and Maerefat [39] identified a relationship between the thermal response index and the ASHRAE thermal sensation scale. Although this model can overcome some limitations of the energy balance-based models, it was developed for an average human population, similar to most other common models. Therefore, the effects of individual parameters are neglected in the mentioned human body models. Hence, it seems that a new individualized thermoregulatory model must be developed to evaluate the thermal conditions of living biological tissue while considering individual differences as well as calculating the actual temperature profiles at the receptor locations. 
1 This paper presents a novel individual human body thermoregulatory model based on the thermal responses of cutaneous thermoreceptors in which the effects of individual characteristics are considered. As noted, the temperature and the temperature change rates at the depth of cutaneous receptors play a significant role in thermal response of occupants. So the main objective of this study is to develop a thermoregulatory bio-heat model to accurately determine the temperature at the thermoreceptors' location by considering the effects of personal characteristics (such as age, gender, body mass index (BMI) and BMR) on human body thermal response. This paper is organized to first provide a background for merits of STB model as a base model. Then the development of the individual thermoregulatory bio-heat (ITB) model is explained in methodology part in detail. Finally, the new individualized model is validated under various steady-state and transient environmental conditions and the performance of the model is investigated for exposure to both cold and heat stress.

\section{Background}

\subsection{STB as a base model}

As previously mentioned, Zolfaghari and Maerefat [38] developed a simplified thermoregulatory bio-heat (STB) model by combining the well-known Pennes' equation and Gagge's 2-node model. In their model, thermoregulatory mechanisms such as shivering, sweating, vasodilatation, and vasoconstriction are considered. Core temperature is defined as a variable dependent upon body energy balance. Most importantly, the STB model can accurately compute the temperature at the location of time-dependent thermoreceptors. Also, in the STB model, the obtained physiological responses are utilized to evaluate the thermal sensation.

\subsection{Thermoreceptors}

Cutaneous thermoreceptors are able to detect heat and cold and determine the sensitivity of skin to the thermal environment. Thermal information of the environment is received by these sensors and transmitted through neural cells to the body's thermoregulatory center. The thermoreceptor response to thermal stimuli is called the frequency response. Hensel [31] found that the frequency response includes two parts, one static and one dynamic; the static part is related to the temperature 
1 of the receptor's location $(T)$, and the dynamic part is dependent upon the temperature change rates

$2\left(\frac{\partial T}{\partial t}\right)$ at the depth of the receptors. Based on Hensel's findings, Ring and de Dear [32] developed a

3 model for assessing thermoreceptor responses. They provided relationships for the frequency

4 response of receptors as follows:

5 Cold receptors:

$$
R S_{\mathrm{cR}}(t)=-k_{s}\left(T\left(x_{\mathrm{cR}}, t\right)-T_{\mathrm{n}, \mathrm{cR}}\right)-k_{\mathrm{d}} \min \left\{0.0,\left(\frac{\partial T(x, t)}{\partial t}\right)_{x=x_{\mathrm{cR}}}\right\}
$$

6

7 Warm receptors:

8

$$
R S_{\mathrm{wR}}(t)=k_{s}\left(T\left(x_{\mathrm{wR}}, t\right)-T_{\mathrm{n}, \mathrm{wR}}\right)-k_{\mathrm{d}} \max \left\{0.0,\left(\frac{\partial T(x, t)}{\partial t}\right)_{x=x_{\mathrm{wR}}}\right\}
$$

where $\mathrm{RS}(\mathrm{t})$ is the frequency response of a thermoreceptor $(\mathrm{Hz})$, and $k_{s}$ and $k_{\mathrm{d}}$ are proportionality constant for the static and dynamic response $\left(K^{-1} S^{-1}\right)$, respectively. Subscripts $\mathrm{cR}$ and $\mathrm{wR}$ are related to cold and warm receptors, respectively. It is noteworthy that cold receptors are generally located at a depth of $0.2 \mathrm{~mm}$ and warm receptors are found at a depth of approximately $0.5 \mathrm{~mm}$ from the skin surface [35].

\subsection{Structure of the STB model}

As shown in Fig. 1, in the STB model, the thickness of skin is subdivided into 3 main layers (epidermis, dermis, and subcutaneous). Each of these layers has different thermal properties which are used in Pennes' equation. The outer layer of skin is very thin, and in it, the rate of blood perfusion is almost zero. This layer is called the epidermis or outer skin. The layer under the outer skin is called the dermis, and the nerve endings related to cold and warm receptors are located in it. The layer under the dermis is called the subcutaneous and connects the skin to muscle tissue. 
19

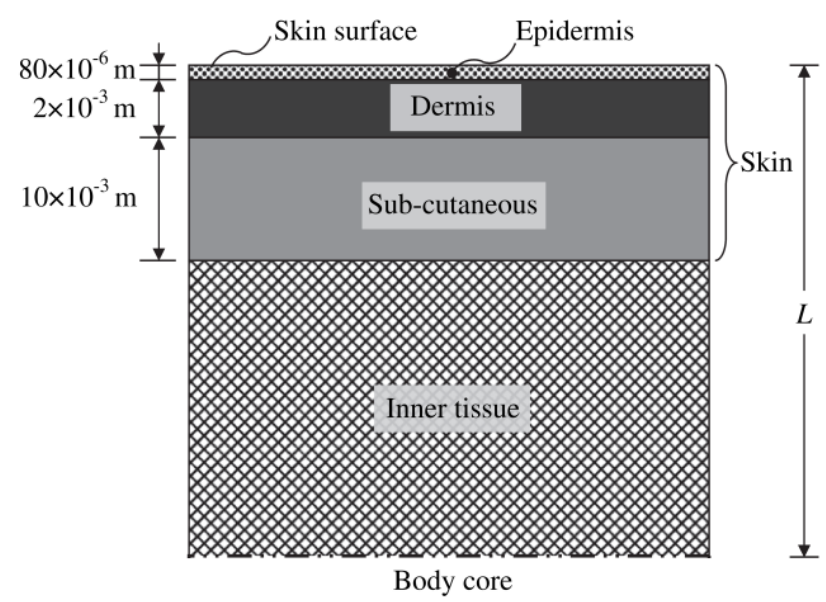

Fig. 1 schematic geometry of skin layers [38].

The main governing equation of the model with time-dependent boundary conditions is as follows:

$$
\rho_{\mathrm{b}} C_{\mathrm{pb}} \frac{\partial T(x, t)}{\partial t}=k_{\mathrm{b}} \frac{\partial^{2} T(x, t)}{\partial x^{2}}+\dot{W}_{\mathrm{bl}} C_{\mathrm{pbl}}\left(T_{\mathrm{art}}-T(x, t)\right)+\dot{Q}_{\mathrm{m}}
$$

where $\rho_{\mathrm{b}}$ is the density $\left(\mathrm{kg} / \mathrm{m}^{3}\right), C_{\mathrm{pb}}$ is the specific heat capacity $(\mathrm{J} / \mathrm{kgK}), k_{\mathrm{b}}$ is the thermal conductivity of tissue $(\mathrm{W} / \mathrm{mK}), \dot{W}_{\mathrm{bl}}$ is the blood perfusion rate $\left(\mathrm{m}^{3} / \mathrm{s} \mathrm{m}^{3}\right), C_{\mathrm{pbl}}$ is the specific heat capacity of blood $(\mathrm{J} / \mathrm{kgK}), T_{\mathrm{art}}$ is the arterial temperature $(\mathrm{K})$, and $\dot{Q}_{\mathrm{m}}$ is the metabolic heat production $\left(\mathrm{W} / \mathrm{m}^{3}\right)$. In order to solve Equation (3), two boundary conditions and an initial condition are required.

Boundary conditions at skin surface:

$$
-k_{\mathrm{b}} \frac{\partial T}{\partial x}=h_{\mathrm{t}}\left(T-T_{\mathrm{a}}\right)+\sigma \varepsilon\left(T^{4}-T_{\mathrm{rd}}^{4}\right)+\left(3.054+16.7 h w_{\mathrm{sk}}\right)\left(0.256 T-3.37-P_{\mathrm{a}}\right)
$$

Boundary conditions at body core:

$$
T_{\mathrm{cr}}^{\text {new }}=T_{\mathrm{cr}}^{\text {old }}+\frac{\Delta \mathrm{t}}{(1-\alpha) \rho_{\mathrm{b}} C_{\mathrm{pb}}}\left[r_{\mathrm{m}} \dot{Q}_{m}-\frac{\left(k_{\mathrm{eff}}+C_{\mathrm{pbl}} \dot{m}_{\mathrm{bl}}\right)\left(T_{\mathrm{cr}}^{\text {old }}-T_{\mathrm{sk}}^{\text {old }}\right)}{l_{\mathrm{b}}}\right]
$$


1 Furthermore, $l_{b}$ represents the ratio of volume of the human body volume $\left(\mathrm{m}^{3}\right)$ to its surface area

$2\left(\mathrm{~m}^{2}\right)$. The amount of the remaining metabolic coefficient $\left(r_{m}\right)$ is calculated from Equation (7), and

$3 \eta_{m}$ is the external mechanical efficiency that can be calculated from Equation (8).

$$
\begin{aligned}
& l_{b}=\frac{V_{b}}{A_{D}} \\
& r_{m}=1-\eta_{m}-0.0014\left(34-T_{a}\right)-0.0173\left(5.87-P_{a}\right) \\
& \eta_{m}=\frac{W}{M}
\end{aligned}
$$

4 In Equations 3, 4, and 5, the physiological parameters such as $\dot{Q}_{\mathrm{m}}, \alpha, w_{\mathrm{sk}}$ and $\dot{m}_{\mathrm{bl}}$ can vary

5 depending on the individual and environmental conditions. Therefore, these parameters are 6 simulated thermoregulatory mechanisms (sweating, shivering, vasodilation, and vasoconstriction).

7 To calculate these parameters, the thermal signals must be defined as similar to Gagge's model.

$$
\begin{aligned}
& W S I G_{\mathrm{cr}}=\operatorname{Max}\left\{0, T_{\mathrm{cr}}-T_{\mathrm{cr}, \mathrm{n}}\right\} \\
& \operatorname{SSIG}_{\mathrm{cr}}=\operatorname{Max}\left\{0, T_{\mathrm{cr}, \mathrm{n}}-T_{\mathrm{cr}}\right\} \\
& W \operatorname{SIG}_{\mathrm{sk}}=\operatorname{Max}\left\{0, T_{\mathrm{sk}}-T_{\mathrm{sk}, \mathrm{n}}\right\} \\
& \operatorname{CSIG}_{\mathrm{sk}}=\operatorname{Max}\left\{0, T_{\mathrm{sk}, \mathrm{n}}-T_{\mathrm{sk}}\right\}
\end{aligned}
$$

8 Cold and warm thermal conditions cause vasomotion of the blood vessels in the human body. This

$$
\begin{aligned}
& \dot{m}_{\mathrm{bl}}=\frac{6.3+200 W S I G_{\mathrm{cr}}}{3600\left(1+0.5 C S I G_{s k}\right)} \\
& \alpha=0.0418+0.745 /\left(3600 \dot{m}_{\mathrm{bl}}+0.585\right)
\end{aligned}
$$

14

$$
w_{\mathrm{sk}}=0.06+0.94\left(\frac{\dot{m}_{\mathrm{rsw}} h_{\mathrm{fg}}}{\dot{Q}_{\text {evap, max }}}\right)
$$

17 The maximum evaporative potential $\left(\dot{Q}_{\text {evap,max }}\right)$ is estimated from the following equation:

The total skin wettedness level $\left(w_{\mathrm{sk}}\right)$ that presents in Equation (4) can be calculated from the following equation [40]: 
$\dot{Q}_{\text {evap,max }}=\left(P_{s k(s)}-P_{a}\right) / R_{e, t}$

1 Sweating is another thermal regulation mechanism that controls body temperature under hot

2 conditions by raising skin wettedness. With regard to the thermal signals defined for body

3 temperature, the sweat rate can be calculated as follows:

$$
\dot{m}_{\mathrm{rsw}}=4.7 \times 10^{-5} W \operatorname{SIG} \mathrm{b} \exp \left(W S I G_{\mathrm{sk}} / 10.7\right)
$$

4 where:

$$
W S I G_{b}=\operatorname{Max}\left\{0, T_{\mathrm{b}}-T_{\mathrm{b}, \mathrm{n}}\right\}
$$

5 and:

$$
\begin{aligned}
& T_{\mathrm{b}}=\alpha T_{\mathrm{sk}}+(1-\alpha) T_{\mathrm{cr}} \\
& T_{\mathrm{b}, \mathrm{n}}=\alpha T_{\mathrm{sk}, \mathrm{n}}+(1-\alpha) T_{\mathrm{cr}, \mathrm{n}}
\end{aligned}
$$

6 Shivering is another important physiological mechanism that regulates body temperature under

7 cold conditions by increasing the metabolic rate. Shivering can be estimated using the following 8 equation:

$$
\begin{aligned}
& \dot{Q}_{\mathrm{m}, \text { hhiv }}=\frac{19.4 \operatorname{CSIG}_{\mathrm{sk}} \operatorname{CSIG}_{\mathrm{cr}}}{l_{\mathrm{b}}} \\
& \dot{Q}_{\mathrm{m}}=\dot{Q}_{\mathrm{m}, \mathrm{act}}+\dot{Q}_{\mathrm{m}, \text { shiv }}
\end{aligned}
$$

9 It must be noted that the governing equations of the STB model should be solved numerically in a one-dimensional computational field.

\section{Methodology}

3.1. New Individualized Thermoregulatory Bio-heat (ITB) model

As shown in Fig. 2, individual characteristics (e.g., weight, height, body fat percentage, maximum cardiac output, acclimation, fitness, and gender) can affect the three main parts of thermoregulatory models: 1) heat transfer between body and environment (passive system) through convection, conduction, radiation, and evaporation mechanisms; 2) thermoregulatory mechanisms (active system), such as shivering and vasoconstriction in cold conditions, sweating and vasodilation in warm conditions; and 3) the thermal response of the thermoreceptor system. All these issues must be considered in the new model. 


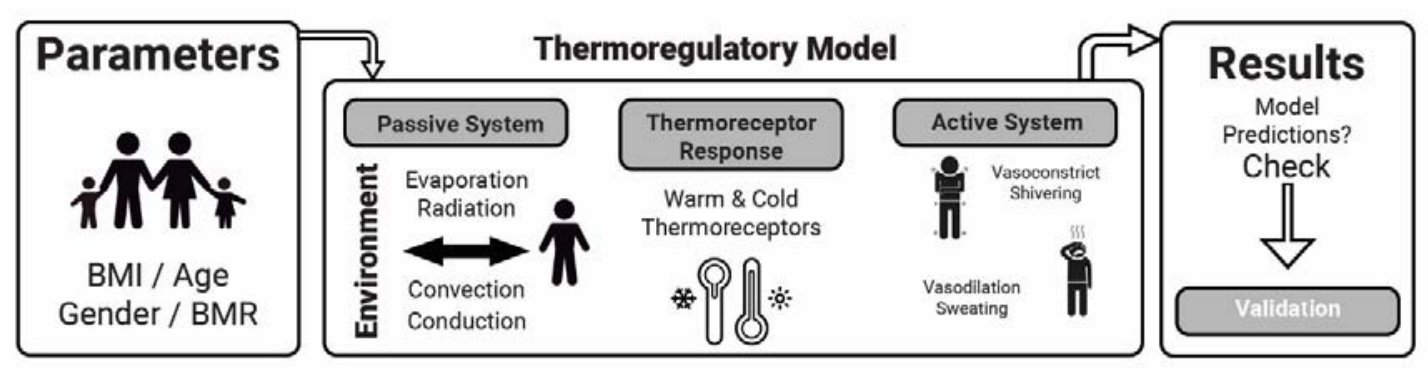

Fig. 2 The schematic for modeling individual characteristics

1

2

3

4

\subsection{Investigation of individual factors}

As previously mentioned, the time-dependent temperatures at the depth of the warm and cold receptors must be determined accurately in order to utilize the frequency response of the thermoreceptors. Previous studies have clearly shown that individual differences can play a significant role in the body thermoregulatory system. Thus, a person's individual characteristics can significantly affect temperature distribution in human tissue. The necessity of developing a bio-heat model that can accurately predict body temperature while taking into account individual parameters is evident. In order to consider the effects of individual factors in the new model, some personal properties, such as blood perfusion rate in tissue, BMR, specific heat capacity, thermal conductivity, sweat production rate, thickness of each body layer (skin, fat, muscle, and bone), and body fat percentage $(\mathrm{BF} \%)$ are evaluated as functions of measurable and available data, i.e. height, weight, and gender, using existing empirical relationships. Subsequently, the time-dependent body temperature is computed using the modified and individualized bio-heat equation. Finally, by utilizing this individual thermoregulatory model, the thermal responses of thermoreceptors can be defined for predicting a person's thermal sensation index under transient conditions.

As presented in Fig. 3, dependent individual affective factors were modeled using independent individual characteristics, and their roles in the bio-heat equation and related boundary conditions were evaluated. Then, the individual physiological characteristics were utilized in the new model.

3.3. Individualized physical model for the human body 
1 According to previous bio-heat models, body tissue can be divided into four main layers: core, 2 muscle, fat, and skin [10]. As shown in Fig. 1, in the STB model, body tissue is subdivided into 3 the human skin as three stratified layers (epidermis, dermis, and subcutaneous) and one layer as 4 inner tissue. In the mentioned model, the geometric information (layer thicknesses) and thermal 5 properties were suggested as an average for the human population.

6 People have different body compositions. The thicknesses of living tissue layers differ for obese 7 and lean people and depend on age and gender [41]. By utilizing individual parameters, the 8 thickness of each main layer of the body and the thermal properties of each layer can be calculated 9 in order to solve the bio-heat equation (Fig. 4). Also, parameters such as total body surface area, $10 \mathrm{BMI}$, and $\mathrm{BF} \%$ can be calculated. Using the individual dependent parameters, the thicknesses of 11 the various layers of the body tissue are obtained from confirmed empirical correlations. Finally, 12 the governing equations are rewritten and should be solved at the new individualized 13 computational domain. 


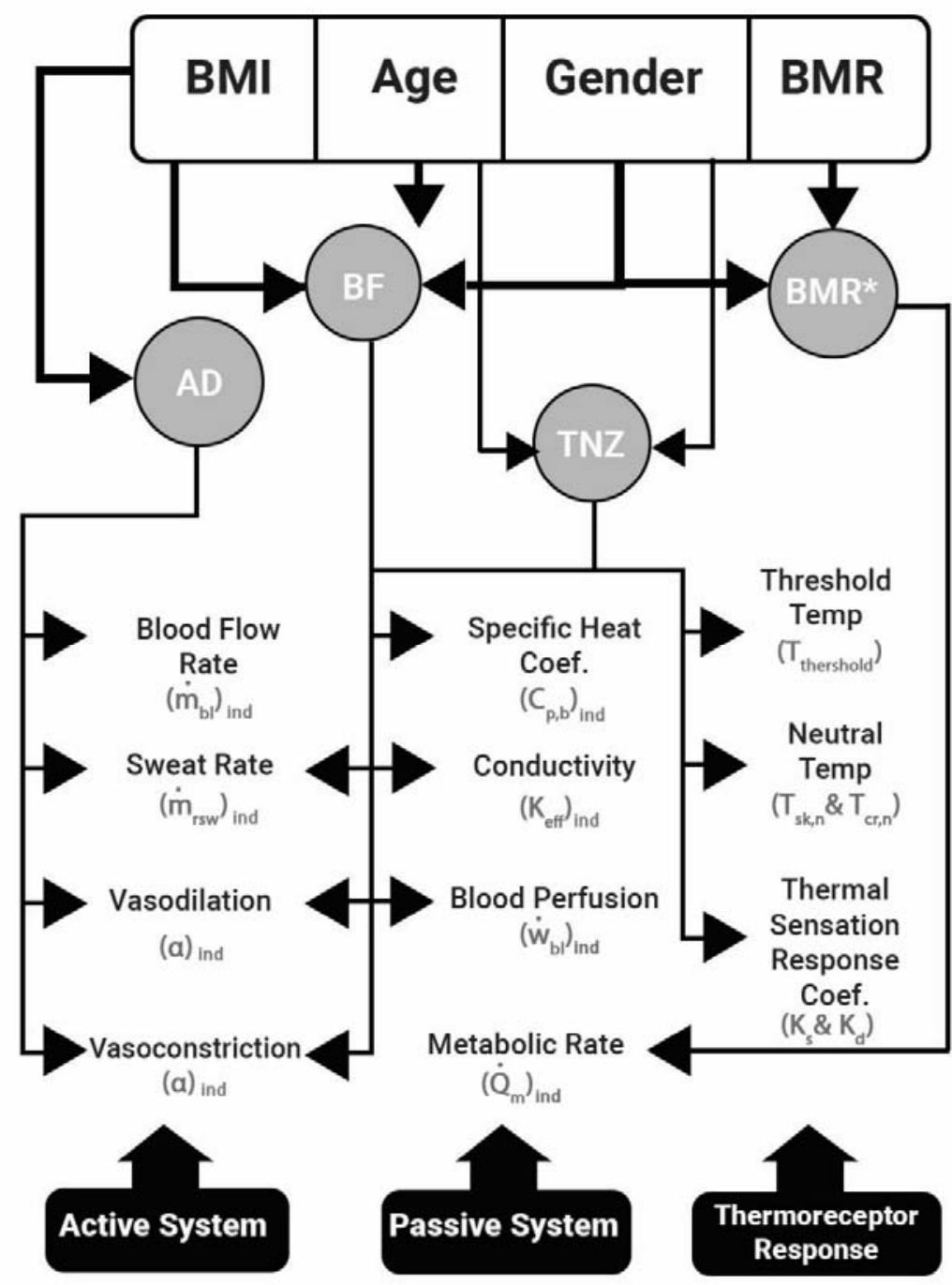

Fig. 3 Schematic diagram for individual parameters and their affection, AD = Body surface area, $\mathrm{BF}=$ Body fat percentage, $\mathrm{TNZ}=$ Thermal neutral zone, $\mathrm{BMR}=$ Basal metabolic rate $B M R^{*}=$ Modified basal metabolic rate, $\mathrm{BMI}=$ Body mass index 


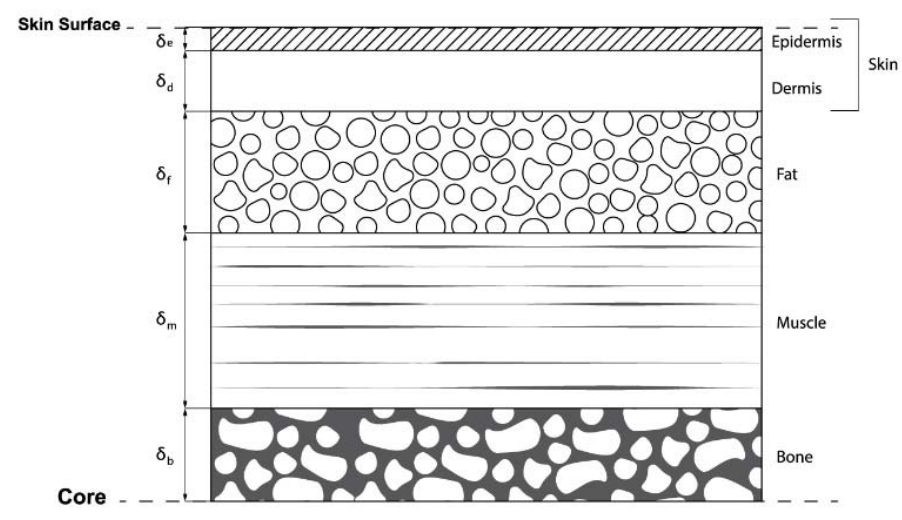

Fig. 4 schematic geometry of heat transfer equation solution domain in tissue layers with variable thickness depend on individual.

2 In most common thermoregulatory models, the characteristics of a standard human body are 3 considered in simulations and individual characteristics are ignored. The specifications of a 4 standard body are a height of $1.83(\mathrm{~m})$, mass of $75(\mathrm{~kg})$, basal metabolic rate of $58.15\left(\mathrm{~W} / \mathrm{m}^{2}\right)$, and 5 male gender [13].

6 The total body surface area is $A_{D}$, which is obtained from the following equation [42].

$$
A_{\mathrm{D}}=0.202 m^{0.425} l^{0.725}
$$

7 Moreover, the gender-based correlations for evaluating the body surface area are as follows [43]:

8

$$
\left(A_{\mathrm{D}}\right)_{\text {male }}=0.0057 l+0.0121 m+0.0882
$$

$$
\left(A_{\mathrm{D}}\right)_{\text {female }}=0.0073 \mathrm{l}+0.0121 \mathrm{~m}-0.2106
$$

9 Body mass index is a statistical index for comparing peoples' body compositions, and it can be obtained by dividing an individual's body mass $(\mathrm{kg})$ by his/her square height $(\mathrm{m})$ as follows [44]:

$$
B M I=\frac{m}{l^{2}}
$$
The thickness of the subcutaneous fat layer plays a significant role in determining body temperature distribution. This parameter can affect thermal conductivity, specific heat capacity, and blood flow rate. First, the BF\% should be obtained from the available values. Among the recommended relationships in various studies, the following equation is in very good agreement with the empirical results [45]. 
$B F=c_{b f, b} \cdot B M I+c_{b f, a} \cdot a g e+c_{b f, 0}$

1 In the above equation, $B F$ is the body fat percentage, $B M I$ stands for body mass index, and age is

2 the age of the subject in years. The coefficients $c_{b f, b}, c_{b f, a}$, and $c_{b f, 0}$ are 1.330, 0.236 and -20.20,

3 for males and 1.210, 0.262 and -6.70 for females, respectively. Moreover, the thickness of the fat

4 layer can be calculated from the following equation:

$\delta_{\text {fat }+ \text { skin }}=0.5 \cdot A S F$

5 where ASF stands for the average skinfold value. This parameter should be obtained through an

6 indirect method by means of density and body fat values. As can be seen, there is a relationship

7 between body density and body fat:

$$
B F=\left[\frac{4.95}{D}-4.50\right] \cdot 100
$$

where $D$ indicates body density. The following equations were proposed to calculate body densities as a relation between skinfolds (SF) or the sum of seven skinfolds (chest, armpit, triceps, shoulders, abdomen, flanks, and thighs) and age while considering gender [46].

For males:

$$
D_{\mathrm{m}}=1.112-10^{-6}\left(434.99 S F+0.55 S F^{2}-288.26 \text { age }\right)
$$

For females:

$$
D_{\mathrm{f}}=1.097-10^{-6}\left(469.71 S F+0.56 S F^{2}-128.28 \text { age }\right)
$$

First, body fat should be evaluated from Equation (27). Afterward, body density is calculated from Equation (29), and then SF can be indirectly obtained from Equation (30) for males and Equation (31) for females. The value of ASF can be calculated as follows:

$$
A S F=S F / 7
$$

Now, the thickness of the fat layer can be obtained from Equation (28). As can be seen, this parameter depends completely upon personal factors (height, weight, age, and gender). Modified thermal resistance and the heat transfer coefficient can also be calculated from the thickness of the fat layer.

The thicknesses of the other layers can be determined using the following relationships [47] based on individual parameters: 


$$
\delta_{i}=\sqrt{\frac{\sum_{i=1}^{4} V_{i}}{\pi L_{p}}}
$$

1

$$
m_{i}=\alpha_{m, i} W
$$

2

$$
V_{i}=m_{i} / \rho_{i}
$$

$$
L_{p}=\frac{A_{D}{ }^{2}}{\left(4 \pi \sum_{i=1}^{4} V_{i}\right)}
$$

4

5

6

7

The subscripts $i=1,2,3,4$ in the above equations correspond to the central core, muscle, fat, and skin layers, respectively. $V_{i}$ indicates the volume of each layer $\left(\mathrm{m}^{3}\right), m_{i}$ is the mass of each layer $(\mathrm{kg})$, and $\alpha_{m, i}$ is the proportion of the weight of each layer (total fat and muscle $=73 \%$, core $=$ $22 \%$, and body skin $=5 \%)[8]$.

The skin structure includes two main layers, the epidermis and the dermis. The epidermis is thin, about $0.075-0.15 \mathrm{~mm}$, and there is no blood perfusion in this layer. The dermis is much thicker than the epidermis and contains sweat glands, thermoregulatory nerves, and vascular systems [48]. Thus, we have:

$$
\delta_{\text {skin }}=\delta_{\text {epidermis }}+\delta_{\text {dermis }}
$$

Therefore, the solution domain of the bio-heat equation in human body tissue with respect to individual characteristics can be defined as follows:

$$
\delta_{t}=\delta_{\text {epidermis }}+\delta_{\text {dermis }}+\delta_{\text {fat }}+\delta_{\text {muscle }}+\delta_{\text {core }}
$$

The thermal properties of each layer are specified in Table 1.

Table 1 Thermal properties of tissue layers $[8,35,47]$. 


\begin{tabular}{lccc}
\hline Properties & $\begin{array}{c}\text { Density } \\
\text { Layer }\end{array}$ & $\begin{array}{c}\text { Specific } \\
\text { heat }\end{array}$ & Conductivity \\
\hline Epidermis & $\left(\frac{\mathbf{k g}}{\mathbf{m}^{3}}\right)$ & $\mathbf{c}\left(\frac{\mathbf{J}}{\mathbf{k g ~ K}}\right)$ & $\boldsymbol{k}\left(\frac{\mathbf{w}}{\mathbf{m K}}\right)$ \\
Dermis & 1200 & 3600 & 0.24 \\
Fat & 1000 & 3300 & 0.45 \\
Muscle & 850 & 2510 & 0.21 \\
Bone & 1115 & 3105 & 0.66 \\
\hline
\end{tabular}

1

2 It should be noted that all of the terms available in the energy balance equations of the 2-node 3 model, which are used in the core boundary condition, have a dimension of power per unit of 4 surface area on the human body $\left(\mathrm{W} / \mathrm{m}^{2}\right)$, while the Pennes' bio-heat equation is written in units 5 of power per volume of the body $\left(\mathrm{W} / \mathrm{m}^{3}\right)$. Therefore, in order to combine the above equations, the 6 individual body characteristic length $\left(l_{b}\right)_{\text {ind }}$ must be defined as follows:

$\left(V_{b}\right)_{\text {ind }}=m / D$

7

$$
\left(l_{b}\right)_{\text {ind }}=\frac{V_{b}}{A_{D}}
$$

8 In the next step, each term of Equations (3), (4), and (5) should be rewritten based on individual 9 characteristics. The schematic diagram for human body thermoregulation is shown in Fig 5. Different thermal terms, such as body thermal conductivity, skin wettedness, the amount of blood perfusion, metabolic rate, blood flow rate between core and skin, etc., are modeled based on personal factors. As shown in Fig. 5, each mentioned term plays a significant role in the human body heat transfer system and in thermoregulatory mechanisms. A new thermoregulatory model can be developed by individualizing these terms. 


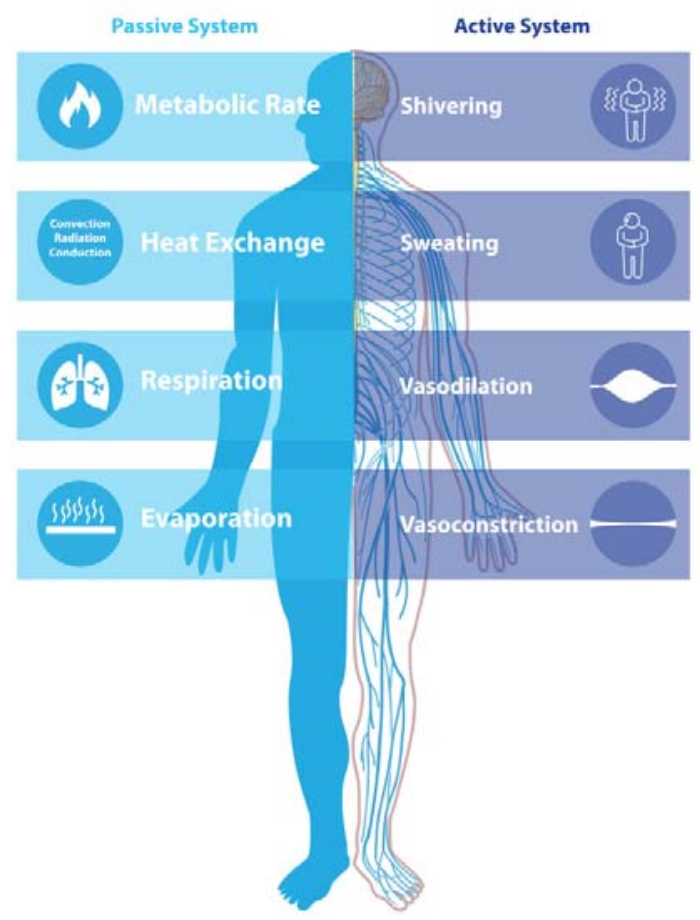

Fig. 5 Schematic diagram for human body thermoregulation by active and passive systems.

1

2 3.4. Individualized thermal coefficients of human body

3 The specific heat capacity for the human body can be modified and related to individual parameters 4 as follows:

$$
C_{\mathrm{p}, \mathrm{b}}=\left(\frac{\text { fat mass }}{m}\right) C_{\mathrm{b}, \mathrm{fat}}+\left(\frac{m-\text { fat mass }}{m}\right) C_{\mathrm{b}, \mathrm{other}}
$$

5

6 To calculate heat transfer through the conduction mechanism, the thermal resistance between the

7 body core and the skin must be estimated. As shown in Fig. 6, thermal resistance between the body 8 core and skin is influenced by individual parameters such as activity level and fat layer thickness, 9 which is expressed by the following equations [17]:

10 where,

$$
R_{\text {core-skin }}=\frac{1}{\left(\frac{1}{R_{\text {skin blood flow }}}+\frac{1}{R_{\text {muscle }}+R_{\text {fat }+ \text { skin }}}\right)}
$$




$$
\begin{aligned}
& R_{\text {muscle }}=\frac{0.05}{1+\left(\frac{M e t-65}{130}\right)} \\
& R_{\text {skin blood flow }}=\frac{1}{\eta \cdot C_{\mathrm{p}, \mathrm{bl}} \cdot m_{\mathrm{bl}}} \\
& R_{\mathrm{fat}+\text { skin }}=0.0048\left(\delta_{\mathrm{fat}+\mathrm{skin}}-2\right)+0.0044
\end{aligned}
$$

1 where $R$ is thermal resistance $\left(\mathrm{m}^{2} \mathrm{~K} / \mathrm{W}\right), \eta$ is blood heat exchange efficiency, $C_{\text {p.bl }}$ is blood heat

2 capacity $(\mathrm{J} / \mathrm{kgK}), \dot{m}_{\mathrm{bl}}$ is skin-blood flow rate $(\mathrm{kg} / \mathrm{s})$, and Met is metabolic rate $\left(\mathrm{W} / \mathrm{m}^{2}\right)$.

3 By means of the mentioned thermal resistance, an individual effective conductivity can be replaced

4 in Equation (5) instead of the average value as follows:

$$
\left(k_{\text {eff }}\right)_{\text {ind }}=\frac{1}{R_{\text {core-skin }}} \times \frac{l_{b}}{\delta_{t}}
$$

5 These modified coefficients can be rewritten in the main bio-heat equation and also in boundary

6 condition equations.
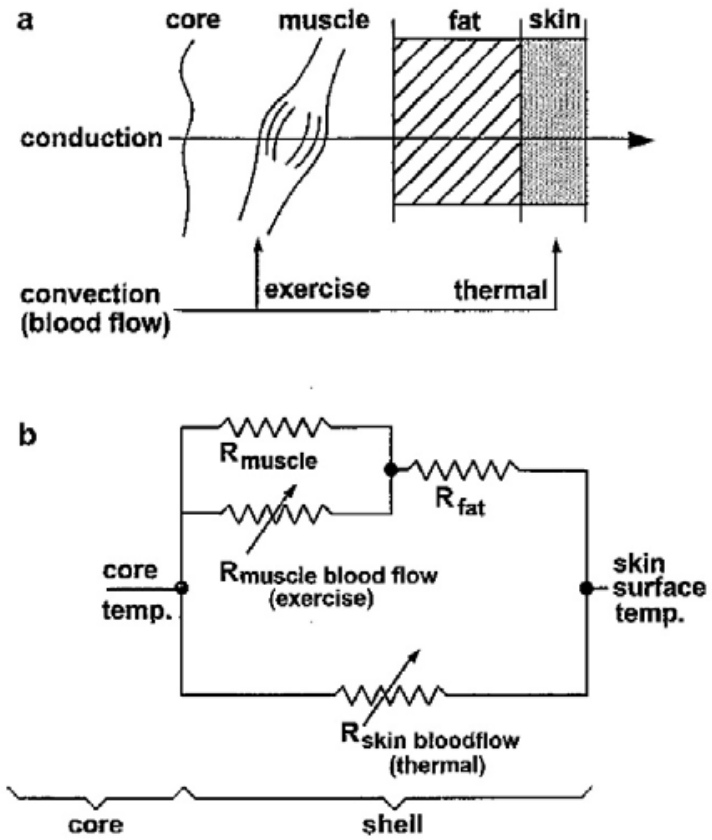

Fig. 6 Schematic of resistors involved in core to skin heat transfer [17].

$8 \quad 3.5$. Individualized human body thermoregulatory mechanisms

9 In the STB model, blood flow rate was used to determine mass accumulation in the skin $(\alpha)$.

10 Now, by obtaining the individual thermal resistance between the body core and the skin [49], $\alpha$ can be modified in the model structure. 
$(\alpha)_{\text {ind }}=0.08+2 R_{\text {core-skin }}$

1 It should be noted that some thermal parameters, such as sweat rate and blood flow rate, are directly

2 affected by the body surface area. These factors have been modeled linearly through correction 3 factor analysis (CFA):

$$
C F A=\left(\frac{A_{D}}{A_{D-\text { standard }}}\right)
$$

4 Thus, the sweat rate and blood flow rate can be modified as in the following equations:

$$
\left(\dot{m}_{\mathrm{rsw}}\right)_{\text {ind }}=C F A \times 4.7 \times 10^{-5} W S I G_{\mathrm{b}} \exp \left(\frac{W S I G_{\mathrm{sk}}}{10.7}\right)
$$

5

$$
\left(\dot{m}_{\mathrm{bl}}\right)_{\text {ind }}=C F A \times \frac{6.3+200 W S I G_{\mathrm{cr}}}{3600\left(1+0.5 C S I G_{\mathrm{sk}}\right)}
$$

6

In Equation (49), the body's warm signal value can be calculated from Equation (18). The neutral body temperature $T_{b, n}$ must be defined with regard to the gender and age of the subject. It should be noted that neutral skin and core temperatures $\left(T_{s k, n}\right.$ and $\left.T_{c r, n}\right)$ can be determined by considering different subpopulations like adult, young, or elderly; obese or lean; and male or female [50, 51]. In this study, neutral skin and core temperature values for standard subject are respectively assumed to be $33.7^{\circ} \mathrm{C}$ and $36.8^{\circ} \mathrm{C}$. Also, the neutral body temperature can be estimated by Eq (20). BMR is another individual factor which significantly affects the body's thermoregulatory system. This parameter can be calculated based on gender, age, and body composition [52]. Among the proposed correlations, the following equation is in very good agreement with the experimental data $[25,53]$ :

$$
(B M R)_{\text {ind }}=58 \times m+1741 \times l-14 \times \text { Age }-470 \times \operatorname{sex}+227
$$

where gender is coded as a dummy variable (man is 0 and woman is 1 ). In this equation, the unit $\mathrm{kJ} /$ day should be converted to Watt $(\mathrm{W})$. The value of heat production per unit area is initialized by considering the person's physical activity level (sedentary or lightly active lifestyle, active or moderately active lifestyle, and vigorous or vigorously active lifestyle) [52]. Then, it can be modified as follows:

$$
C F B=\left(\frac{B M R_{\text {ind }}}{B M R_{\mathrm{st}}}\right)
$$


2 Therefore,

$$
\dot{Q}_{\mathrm{m}}=C F B \times \dot{Q}_{\mathrm{m}, \mathrm{act}}+\frac{19.4 C S I G_{\mathrm{sk}} C S I G_{\mathrm{cr}}}{\left(l_{b}\right)_{\text {ind }}}
$$

3 The second term of the equation above expresses the additional metabolic rate caused by the 4 body's shivering mechanism under cold conditions. Cold signals of the skin and core should be 5 determined based on the neutral temperatures associated with the age and gender of the person.

6 In the discussed equations, the cardiac output can significantly influence blood perfusion $\left(\dot{W}_{\mathrm{bl}}\right)$ in 7 Pennes' equation and blood flow rate $\left(\dot{m}_{\mathrm{bl}}\right)$ which appears in Gagge's model. The cardiac output 8 is the product of heart rate or, simply, is the amount of blood pumped by the heart. Thus, cardiac 9 output is an individual parameter that can play an important role in human body thermoregulation. 10 In the following equation, the cardiac output is obtained based on individual characteristics [14, $1125]$ :

$$
(C O)_{\text {ind }}=0.024 \times m-0.057 \times \text { Age }-0.305 \times \operatorname{sex}+4.544
$$

12 A correction factor is obtained from the following equation:

$$
\mathrm{COF}=\left(\frac{\mathrm{CO}_{\text {ind }}}{\mathrm{CO} \mathrm{St}_{\mathrm{st}}}\right)
$$

13 Now,

$$
\left(\dot{m}_{\mathrm{bl}}\right)_{i n d}=\operatorname{COF} \times\left(\frac{6.3+200 W S I G_{\mathrm{cr}}}{3600\left(1+0.5 C S I G_{s k}\right)}\right)
$$

14

15

$$
\left(\dot{W}_{\mathrm{bl}}\right)_{\text {ind }}=\operatorname{COF} \times\left\{\begin{array}{rr}
0 & x<\delta_{e} \\
0.5 \times 0.00125 & \delta_{e} \leq x \leq \delta_{e}+\delta_{d} \\
0.00125 & \delta_{e}+\delta_{d} \leq x \leq \delta_{e}+\delta_{d}+\delta_{f} \\
0.00125 & \delta_{e}+\delta_{d}+\delta_{f} \leq x \leq \delta_{e}+\delta_{d}+\delta_{f}+\delta_{m}
\end{array}\right.
$$

16 3.6. The new individual thermoregulatory (ITB) model algorithm

The schematic diagram provided in Fig. 7 shows the procedure of the thermoregulatory model based on thermoreceptor responses. As illustrated, the time-dependent temperature at the depth of the warm and cold cutaneous receptors is computed while considering the boundary conditions at 
1 skin surface and core. The thermoreceptor response has static and dynamic parts. The static part is

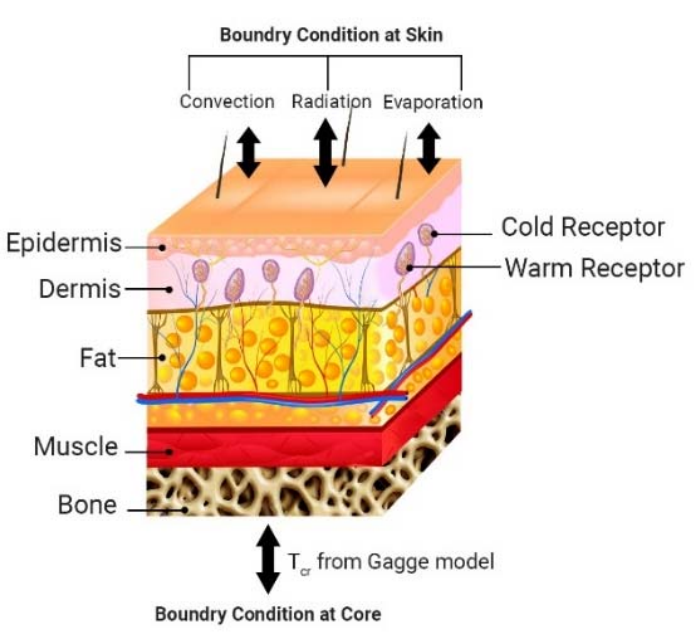

related to the temperature of the thermoreceptor $T\left(x_{\mathrm{R}}, t\right)$, and the dynamic part is dependent upon the rate of temperature change at the depth of the thermoreceptors $\left(\frac{\partial T(x, t)}{\partial t}\right)_{x=x_{\mathrm{R}}}$. By receiving these responses from cutaneous thermoreceptors, the brain can analyze the body's thermal conditions and order the necessary actions to achieve thermal satisfaction.

The process flowchart of the new individual model is outlined in Fig. 8. In this model, a number of available and measurable personal factors are given as input data. Next, the main equations are rewritten according to individual characteristics and resolved at any time step. It is worth noting that, in the present study, the governing equations (main and auxiliary) are solved numerically in a one-dimensional computational field. For this purpose, the implicit finite differences method was used. Ultimately, the time-dependent temperature distribution in tissue is determined. 


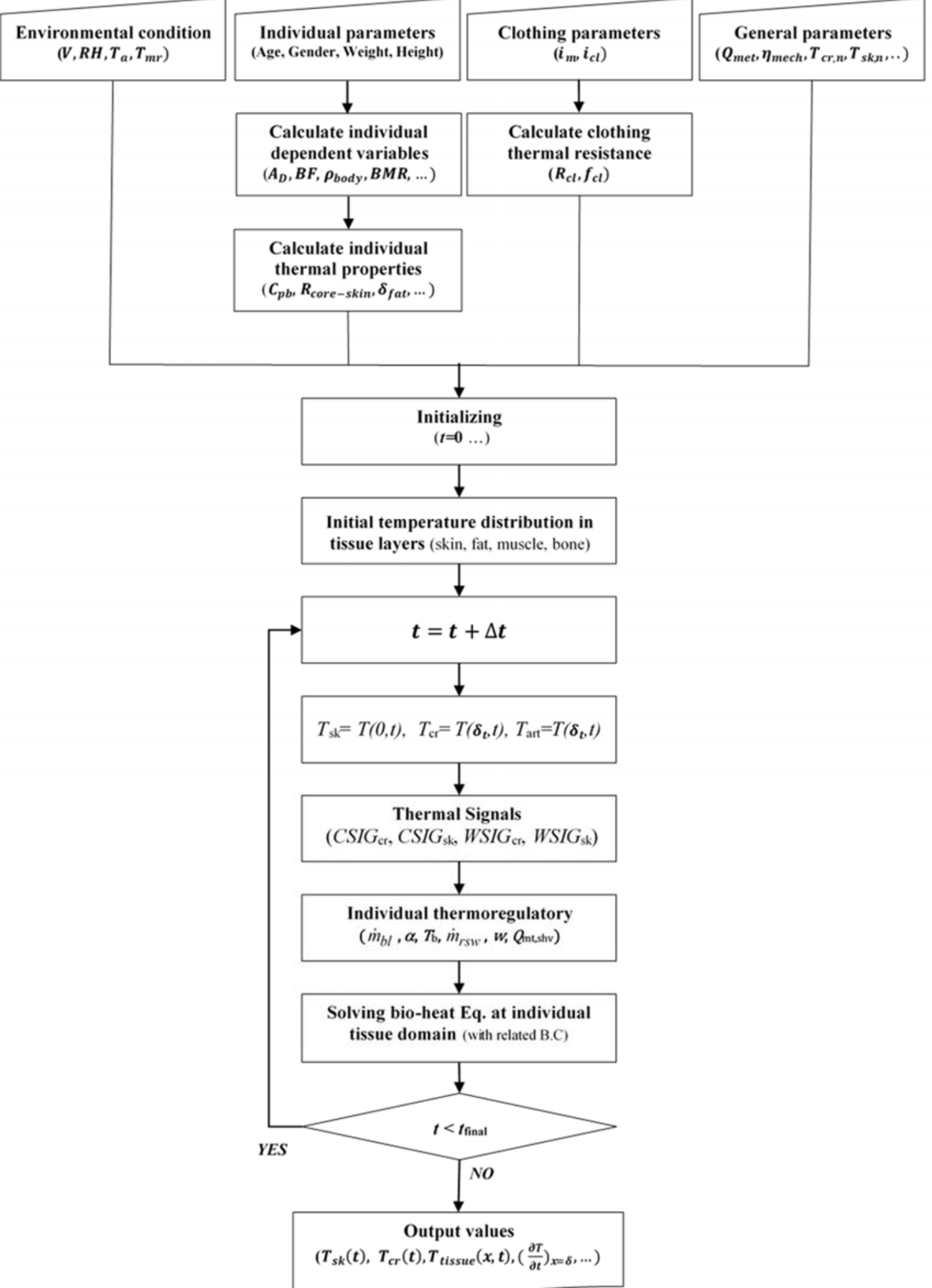

Fig. 8 Flow chart for the present individual thermoregulatory bio-heat (ITB) model 


\section{$1 \quad$ 3.7. Validation statistics}

2 For the evaluation of the model changes in terms of model improvements against experimental

3 data, several parameters were calculated in the comparison of the data with different studies that

4 is to follow:

5 A: Maximum Errors

6 B: Mean absolute error (MAE):

$7 \quad\left(\sum_{1}^{n} \mid\right.$ actual data - simulated data $\left.\mid\right) / n$

8 C: Mean absolute percentage error (MAPE):

$9 \quad \frac{100}{\mathrm{n}} \times\left(\sum_{1}^{n} \frac{\mid \text { actual data }- \text { simulated data } \mid}{\mid \text { actual data } \mid}\right)$

D: Change in error:

$\left(\left(\mathrm{MAE}_{\text {old model }}-\mathrm{MAE}_{\text {new model }}\right) / \mathrm{MAE}_{\text {old model }}\right) \times 100$

In addition, for those datasets where sufficient individual conditions were available, a statistical comparison was made of the improvement in the mean absolute error for that dataset, by using pairwise comparison t-tests. A p-value of 0.05 was chosen to define significance of the improvements. Some paired samples t-tests were conducted to compare mean absolute error for datasets that simulated by the present model and a standard model.

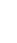
9

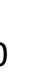

1




\section{Results and Discussion}

In this section, the new developed model is validated against experimental data and simulated results from other models. It should be noted that mean skin temperature and core temperature are strongly related to human body thermoregulation and they are significant indicators of the thermal sensation index [54]. Therefore, they are used to validate the accuracy of the new model.

The new individual model was evaluated under various steady-state and transient environmental conditions. The performance of the model was investigated for exposure to both cold and hot stress.

In the first case, the subjects were exposed to various steady-state warm conditions as in the study of Li et al. [47]. The individual characteristics and thermal conditions (categorized in three series of $\mathrm{A}, \mathrm{B}$, and C) of the participants are listed in Tables 2 and 3, respectively. Participants were exposed to the mentioned thermal conditions for $120 \mathrm{~min}$ to reach steady-state conditions. During the experiments of Li et al. [47], the subjects had normal sedentary office activities ( $\approx 1.2$ met) and their clothing insulation was estimated to be about 0.26 clo (short-sleeved shirts, shorts, and lightweight shoes). At the end of the experiment time for each mentioned environmental condition, the mean skin temperature simulated by the present individualized model was compared with the results of the STB model and the empirical results [47]. These comparisons are illustrated in Figs. 9, 10, and 11 for conditions A, B, and C, respectively.

Table 2. Individual characteristics of participants in the experiment [47].

\begin{tabular}{lllllll}
\hline Subject & Am & Af & Bm & Bf & Cm & Cf \\
\hline Gender & $\begin{array}{l}\text { Male } \\
(\mathrm{n}=10)\end{array}$ & $\begin{array}{l}\text { Female } \\
(\mathrm{n}=10)\end{array}$ & $\begin{array}{l}\text { Male } \\
(\mathrm{n}=10)\end{array}$ & $\begin{array}{l}\text { Female } \\
(\mathrm{n}=10)\end{array}$ & $\begin{array}{l}\text { Male } \\
(\mathrm{n}=10)\end{array}$ & $\begin{array}{l}\text { Female } \\
(\mathrm{n}=10)\end{array}$ \\
Age (year) & $24 \pm 1$ & $24 \pm 1$ & $23 \pm 1$ & $24 \pm 1$ & $23 \pm 1$ & $24 \pm 1$ \\
Height $(\mathrm{cm})$ & $173 \pm 5$ & $160 \pm 7$ & $175 \pm 5$ & $159 \pm 4$ & $172 \pm 6$ & $160 \pm 3$ \\
Weight $(\mathrm{kg})$ & $61 \pm 4$ & $50 \pm 6$ & $67 \pm 10$ & $46 \pm 4$ & $63 \pm 9$ & $48 \pm 5$ \\
\hline
\end{tabular}


1 Table 3 Experiment schedule and conditions [47].

\begin{tabular}{|c|c|c|c|c|c|c|c|c|c|}
\hline Series & $\mathbf{A}$ & & & B & & & $\mathbf{C}$ & & \\
\hline Conditions & 1 & 2 & 3 & 1 & 2 & 3 & 1 & 2 & 3 \\
\hline Air temperature $\left({ }^{\circ} \mathrm{C}\right)$ & 26.9 & 28.9 & 31.0 & 25.6 & 28.0 & 29.9 & 28.0 & 28.1 & 32.0 \\
\hline Relative humidity (\%) & 54 & 55 & 51 & 41 & 40 & 60 & 90 & 90 & 80 \\
\hline Air velocity $(\mathrm{m} / \mathrm{s})$ & 0.11 & 0.11 & 0.14 & 0.08 & 0.07 & 0.09 & 0.6 & 0.79 & 0.79 \\
\hline Clothing insulation (clo) & 0.26 & 0.26 & 0.26 & 0.26 & 0.26 & 0.26 & 0.26 & 0.26 & 0.26 \\
\hline Activity level (met) & 1.2 & 1.2 & 1.2 & 1.2 & 1.2 & 1.2 & 1.2 & 1.2 & 1.2 \\
\hline
\end{tabular}

2

As shown in Figs. 9-11, the results of the present model are in good agreement with the experimental data. Also, in Table 4 mean absolute errors, margin of errors and mean absolute percentage errors between measurement data and simulated results from the present model and STB model are calculated. For example, in Table 4, by using the ITB model instead of the STB model, the mean absolute error was reduced from $0.51^{\circ} \mathrm{C}$ to $0.12{ }^{\circ} \mathrm{C}, 0.48{ }^{\circ} \mathrm{C}$ to $0.13{ }^{\circ} \mathrm{C}$, and $0.3{ }^{\circ} \mathrm{C}$ to $0.1^{\circ} \mathrm{C}$ for cases $\mathrm{Am}$-con1, Bf-con2, and $\mathrm{Cf}$-con1, respectively. In other words, all mean absolute percentage errors of the present model are lower than STB model. This was confirmed in the result of the statistical comparison of the two model's results over 18 conditions, which indicated the present model to have significantly lower errors $(t(17)=6.94, p<0.001)$. According statistical validation, all obtained results from the present model in eighteen compared cases, lie within the confidence interval of the population means.

Moreover, the new ITB model can predict the mean skin temperature of both males and females more accurately than the STB model. As can be seen, the results obtained from the nonindividualized model (STB model) are the same for both male and female subjects (Am-Af, Bm$\mathrm{Bf}$, and $\mathrm{Cm}-\mathrm{Cf}$ ) under various conditions, while the simulation results of the present model are closer to the measured data of Li et al. [47].

It should be noted in the Li et al. [47] study beside experimental researches, they have worked on a thermoregulatory model that focused on average population of Chinese people under warm conditions and used energy equation in a one-dimensional cylindrical coordinate. The ITB model is more accurate and can estimate the human body thermoregulation in wider range of environment 
1 conditions in relation to the Li et al. [47] model. In addition, the ITB model be able to predict the 2 thermal response of the cutaneous receptors individually.

3

4

5

6

7

8

9

10

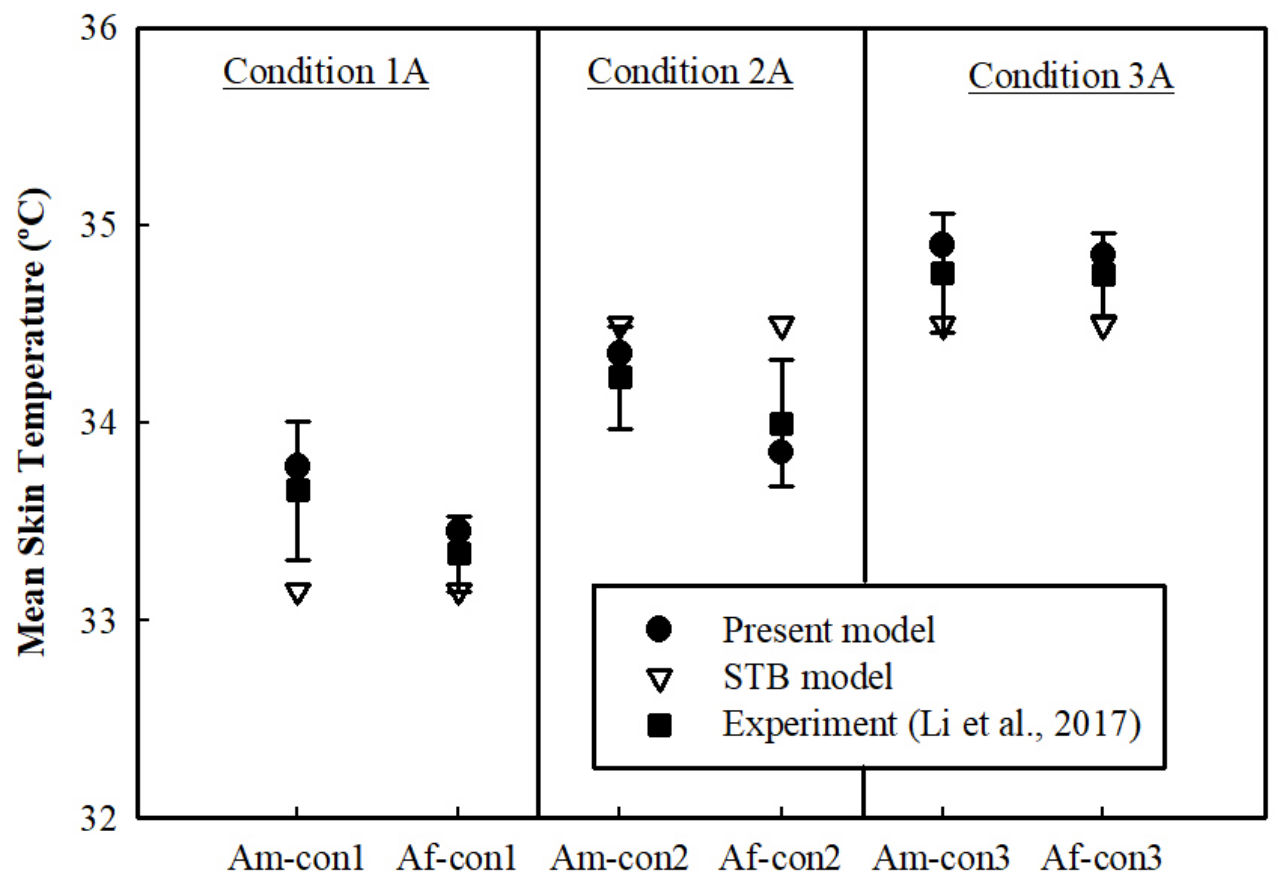

Fig. 9 Comparison of the measured mean skin temperatures [47] with the results of STB model and the present model for Am and Af cases (the error bars show the $95 \%$ confidence interval for the population means). 
2

4

5

6

7

8

9

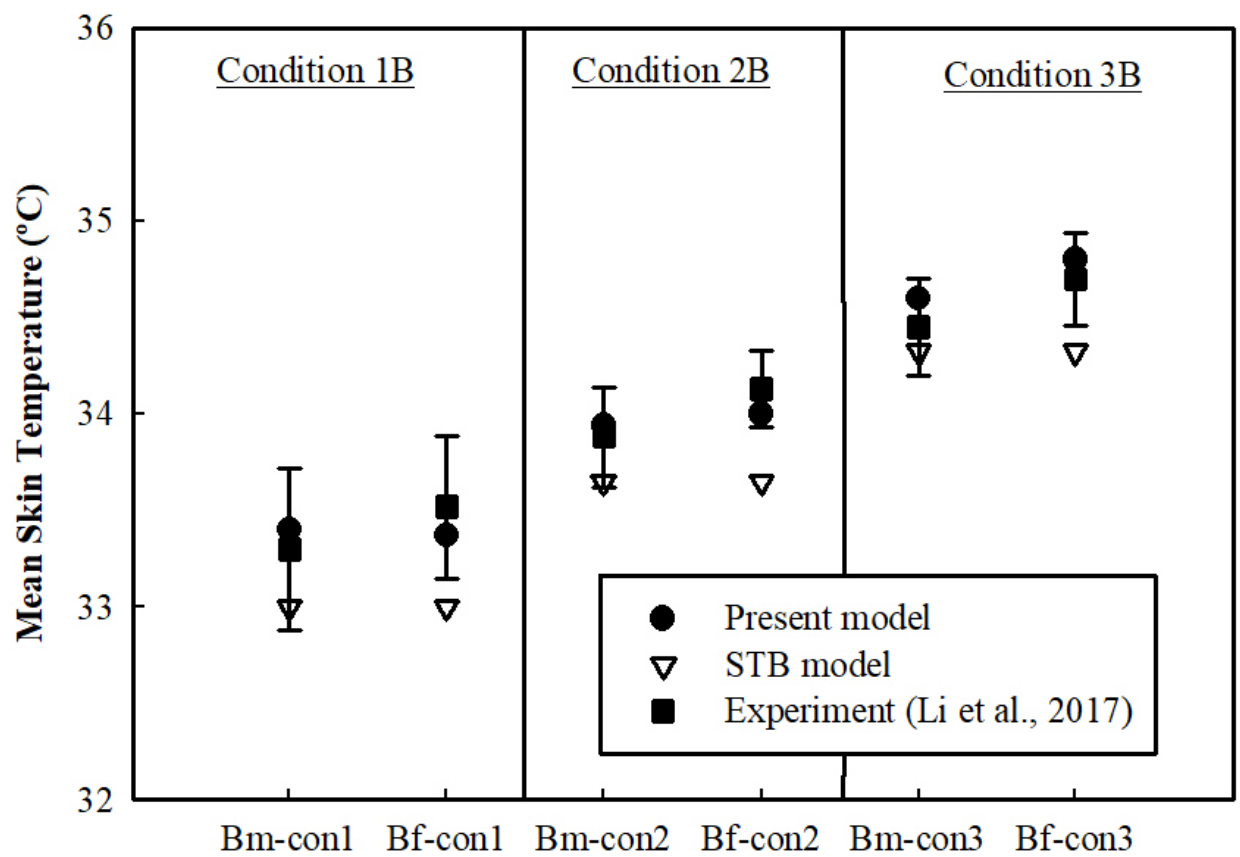

Fig.10 Comparison of the measured mean skin temperatures [47] with the results of STB model and the present model for Bm and Bf cases (the error bars show the $95 \%$ confidence interval for the population means).

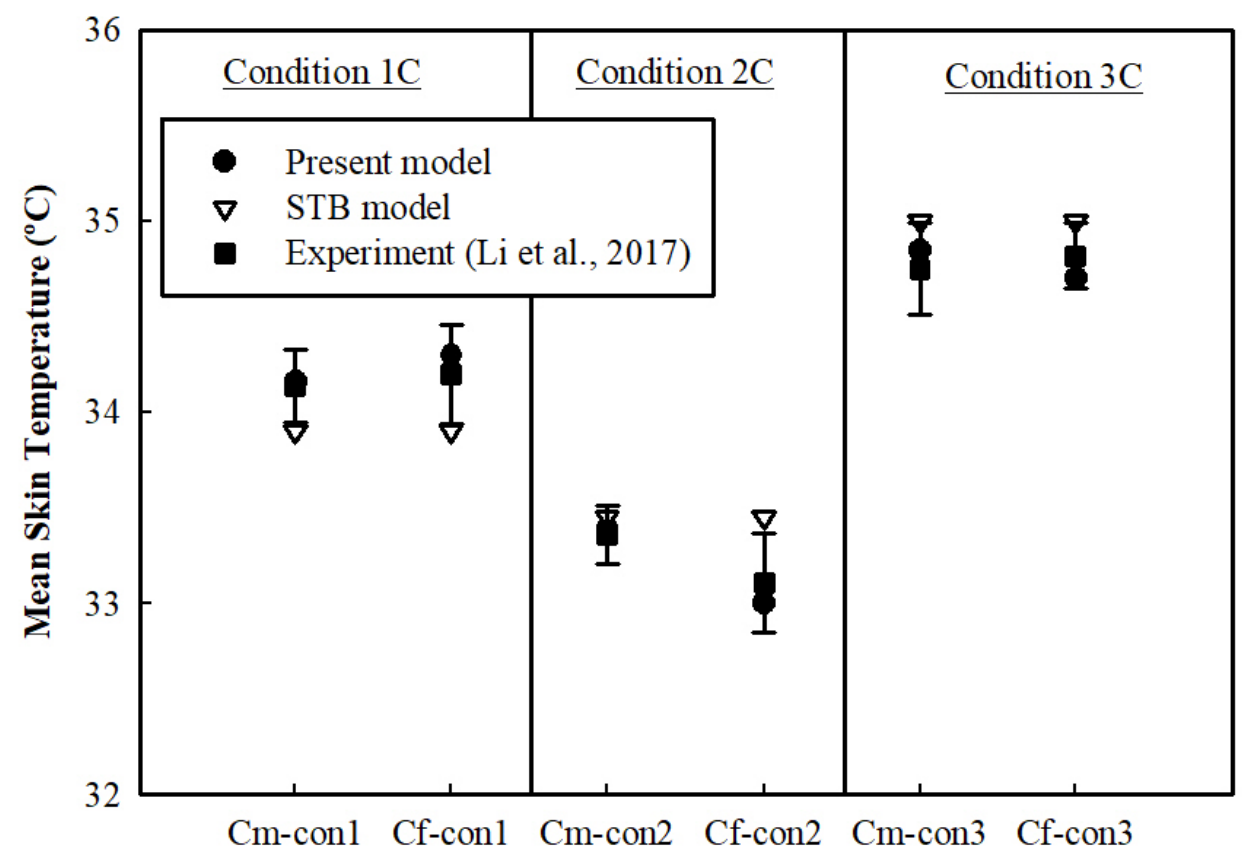

Fig.11 Comparison of the measured mean skin temperatures [47] with the results of STB model and the present model for $\mathrm{Cm}$ and $\mathrm{Cf}$ cases (the error bars show the $95 \%$ confidence interval for the population means). 
7 Table 4 Mean absolute errors (MAE), margin of errors (ME) and mean absolute percentage errors 8 (MAPE) between measurement data and simulated results from the present model (ITB model) 9 and STB model for mean skin temperature $\left(T_{\text {sk,mean }}\right)$. ( $\checkmark$ : lie within the confidence interval, $\mathbf{X}$ :

Don't lie within the confidence interval)

\begin{tabular}{|c|c|c|c|c|c|c|c|c|}
\hline \multirow[b]{2}{*}{ Subject } & \multirow[b]{2}{*}{ Condition } & \multicolumn{2}{|c|}{$\begin{array}{c}\text { Mean Absolute Error } \\
\operatorname{MAE}\left({ }^{\circ} \mathrm{C}\right)\end{array}$} & \multicolumn{3}{|c|}{$\begin{array}{c}\text { Margin of Error }\left({ }^{\circ} \mathrm{C}\right) \\
95 \% \text { confidence } \\
\text { interval }\end{array}$} & \multicolumn{2}{|c|}{$\begin{array}{l}\text { Mean Absolute } \\
\text { Percentage Error } \\
\text { MAPE }(\%)\end{array}$} \\
\hline & & $\begin{array}{c}\text { STB } \\
\text { Model }\end{array}$ & $\begin{array}{l}\text { Present } \\
\text { Model }\end{array}$ & $\mathrm{ME}$ & & lels & $\begin{array}{c}\text { STB } \\
\text { Model }\end{array}$ & $\begin{array}{l}\text { Present } \\
\text { Model }\end{array}$ \\
\hline \multirow[t]{3}{*}{$\mathrm{Am}$} & 1 & 0.51 & 0.12 & 0.35 & STB $X$ & ITB $\checkmark$ & 1.51 & 0.35 \\
\hline & 2 & 0.27 & 0.12 & 0.26 & STB $x$ & ITB $\checkmark$ & 0.78 & 0.35 \\
\hline & 3 & 0.26 & 0.14 & 0.3 & $\mathrm{STB} \checkmark$ & ITB $\checkmark$ & 0.74 & 0.40 \\
\hline \multirow[t]{3}{*}{ Af } & 1 & 0.19 & 0.11 & 0.19 & STB & ITB & 0.56 & 0.32 \\
\hline & 2 & 0.5 & 0.15 & 0.32 & $\operatorname{sTB} x$ & ITB $\checkmark$ & 1.47 & 0.44 \\
\hline & 3 & 0.25 & 0.1 & 0.21 & STB $x$ & ITB $\checkmark$ & 0.71 & 0.28 \\
\hline \multirow[t]{3}{*}{$\mathrm{Bm}$} & 1 & 0.3 & 0.1 & 0.42 & STB & ITB $\checkmark$ & 0.90 & 0.30 \\
\hline & 2 & 0.23 & 0.06 & 0.26 & $\mathrm{STB} \checkmark$ & ITB $\checkmark$ & 0.67 & 0.17 \\
\hline & 3 & 0.125 & 0.15 & 0.25 & $\mathrm{STB} \checkmark$ & ITB $\checkmark$ & 0.36 & 0.43 \\
\hline \multirow[t]{3}{*}{$\mathrm{Bf}$} & 1 & 0.52 & 0.15 & 0.37 & STB $x$ & ITB & 1.55 & 0.44 \\
\hline & 2 & 0.48 & 0.13 & 0.2 & $\operatorname{sTB} x$ & ITB $\checkmark$ & 1.40 & 0.38 \\
\hline & 3 & 0.375 & 0.1 & 0.24 & $\operatorname{sTB} x$ & ITB $\checkmark$ & 1.08 & 0.28 \\
\hline
\end{tabular}




\begin{tabular}{lllllllll}
\hline Cm & 1 & 0.24 & 0.02 & 0.19 & STB $~$ & ITB & 0.70 & 0.05 \\
& 2 & 0.09 & 0.04 & 0.15 & STB $\checkmark$ & ITB $\checkmark$ & 0.26 & 0.11 \\
& 3 & 0.25 & 0.1 & 0.24 & STB $\times$ & ITB $\checkmark$ & 0.71 & 0.28 \\
\hline Cf & 1 & 0.3 & 0.1 & 0.26 & STB $\times$ & ITB $\checkmark$ & 0.87 & 0.29 \\
& 2 & 0.34 & 0.11 & 0.26 & STB $\times$ & ITB $\checkmark$ & 1.02 & 0.33 \\
& & 0.18 & 0.12 & 0.17 & STB & ITB & 0.51 & 0.34 \\
\hline
\end{tabular}

1

2

Another case used to examine the performance of the present model is the study of Li et al. [47], the empirical conditions of which considered ten male and ten female healthy subjects with different body compositions under a transient warm step change. Table 5 presents the individual characteristics of the experiment participants. The experiment schedule and environmental conditions are illustrated in Fig. 12. In the mentioned test case, participants first experienced the step change from a neutral to a typically warm condition; they stayed in this situation for $1800 \mathrm{~s}$. Finally, they returned to the neutral environment through another step-change thermal process.

In Fig. 13, the mean skin temperature predicted by the new individual model for different subjects (S1 and S2) is compared with the measured data [47] and simulated results obtained using Gagge's model (non-individual model) during the experiment. It can be seen that the results of the new model are in good agreement with the empirical results. In Table 6, mean absolute errors and maximum errors between measured data and simulated results from the present model and Gagge's model as a standard model are shown. As illustrated in Fig. 13, the Gagge's model as a populationbased thermal comfort model cannot estimate the mean skin temperature for S1 and S2 (males and females with specified personal parameters) individually. Also, the maximum error for S1 and S2 in the prediction of mean skin temperature is decreased from $0.54{ }^{\circ} \mathrm{C}$ to $0.39{ }^{\circ} \mathrm{C}$ and from $0.89{ }^{\circ} \mathrm{C}$ to $0.48{ }^{\circ} \mathrm{C}$, respectively (Table 6). Moreover, the mean absolute error for the results of the new individual model is decreased from $0.52{ }^{\circ} \mathrm{C}$ to $0.39{ }^{\circ} \mathrm{C}(\mathrm{S} 2)$. As illustrated in Table 6 , in this case we can improve our predictions by simulating with the present model instead of Gagge model 19\% and $25 \%$ for the mean of S1 group and S2 group respectively.

Table 5 Individual characteristics of volunteers who participated in Li et al.'s [47] experiment. 


\begin{tabular}{lcc}
\hline Subject Groups & S1 & S2 \\
\hline Gender & Male (n=10) & Female (n=10) \\
Age (year) & $24 \pm 1$ & $24 \pm 1$ \\
Height (cm) & $170 \pm 7$ & $159 \pm 6$ \\
Weight (kg) & $58 \pm 5$ & $51 \pm 8$ \\
Activity level (met) & 1.0 & 1.0 \\
Clothing insulation (clo) & 0.4 & 0.4 \\
\hline
\end{tabular}

1

\begin{tabular}{|c|c|c|c|c|}
\hline Velocity & $0.05 \mathrm{~m} / \mathrm{s}$ & $0.2 \mathrm{~m} / \mathrm{s}$ & $0.06 \mathrm{~m} / \mathrm{s}$ & \\
\hline RH & $77.20 \%$ & $56.10 \%$ & $75.40 \%$ & \\
\hline Air temp. & $26^{\circ} \mathrm{C}$ & $33.8^{\circ} \mathrm{C}$ & $26.2^{\circ} \mathrm{C}$ & \\
\hline Condition & Neutral & Warm & Neutral & {$[\mathrm{min}]$} \\
\hline Level & Phase I & Phase II & Phase III & \\
\hline Time & 15 & & 30 & 60 \\
\hline
\end{tabular}

Fig. 12 Schedule and conditions of Li et al. [47] experiment. 
19

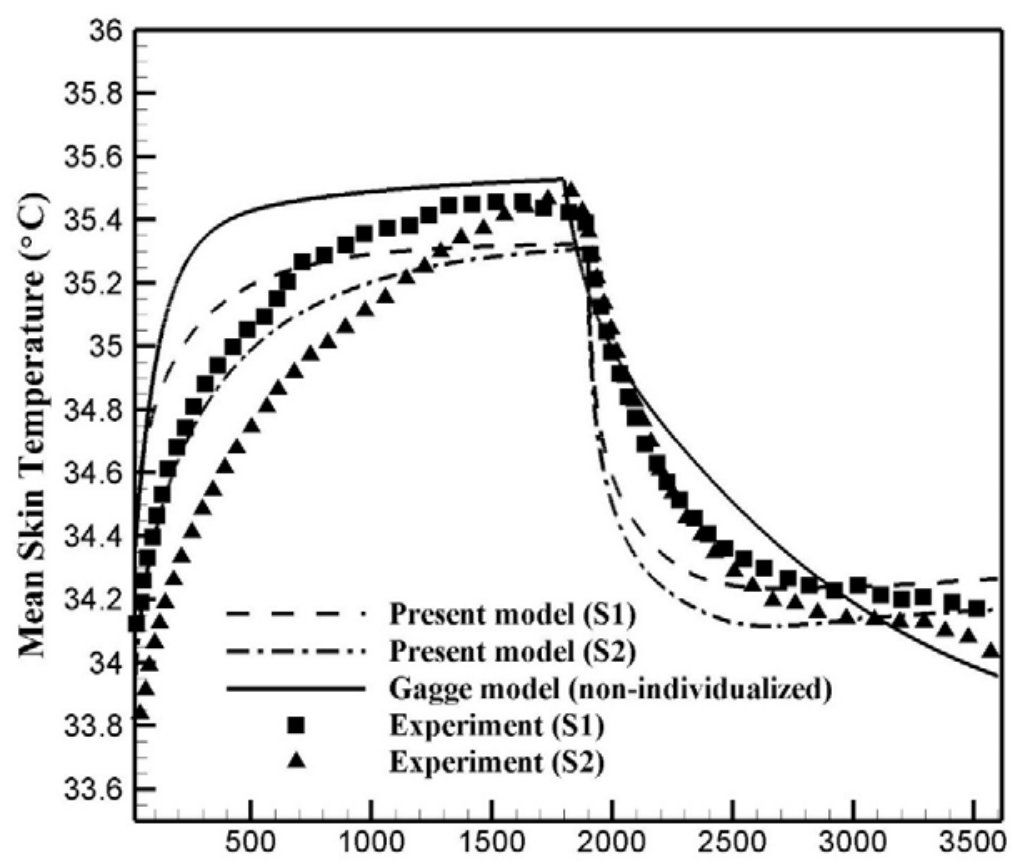

Time (s)

Fig.13 Comparison of the measured mean skin temperatures [47] with the results of Gagge model and the present ITB model for subjects S1 and S2.

Table 6 Mean absolute errors (MAE) and maximum errors between measurement data and simulated results from the present model and Gagge's model for mean skin temperature $\left(T_{\text {sk,mean }}\right)$.

\begin{tabular}{lccccc}
\cline { 2 - 5 } & $\begin{array}{c}\text { Mean Absolute Error } \\
(\mathrm{MAE})\left({ }^{\circ} \mathrm{C}\right)\end{array}$ & \multicolumn{2}{c}{$\begin{array}{c}\text { Maximum Error } \\
\left({ }^{\circ} \mathrm{C}\right)\end{array}$} & $\begin{array}{c}\text { Change in Error } \\
(\%)\end{array}$ \\
\cline { 2 - 6 } $\begin{array}{l}\text { Subject } \\
\text { Groups }\end{array}$ & $\begin{array}{c}\text { Gagge } \\
\text { Model }\end{array}$ & $\begin{array}{c}\text { Present } \\
\text { Model }\end{array}$ & $\begin{array}{c}\text { Gagge } \\
\text { Model }\end{array}$ & $\begin{array}{c}\text { Present } \\
\text { Model }\end{array}$ & $\frac{\left(\mathrm{MAE}_{\text {Gagge }}-\mathrm{MAE}_{\text {Present }}\right)}{\mathrm{MAE}_{\text {Gagge }}} \times 100$ \\
\hline S1 & 0.42 & 0.34 & 0.54 & 0.39 & 19 \\
S2 & 0.52 & 0.39 & 0.89 & 0.48 & 25 \\
\hline
\end{tabular}

To evaluate the performance of the newly developed ITB model at different activity levels, the core temperatures predicted by the new individual model were compared with the results of Yokota 
1 et al. [55] in which the subjects were wearing a battle dress uniform (BDU) and walking at 1.34

2

3

4

5

6

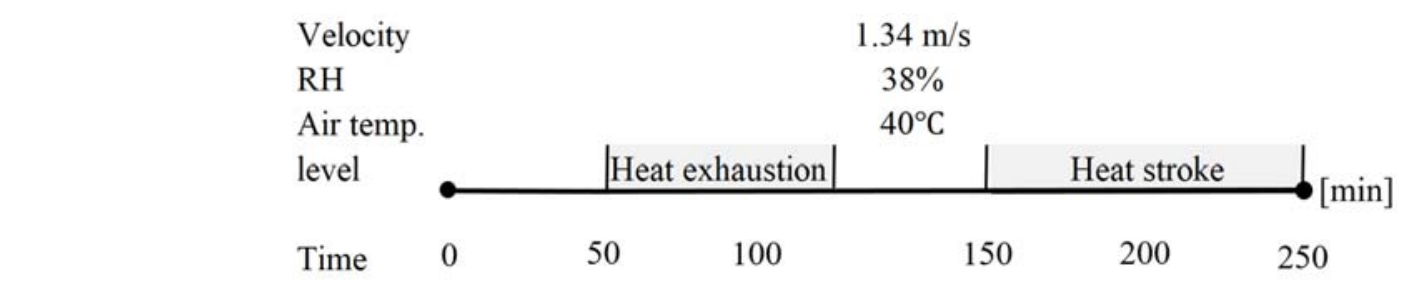

Fig. 14 Schedule and conditions of Yokota et al. [55] study. $\mathrm{m} / \mathrm{s}$ (2.6 met) during a schedule as shown in Fig. 14. In addition, the results obtained from the ITB model (Fig. 15) were compared with the results of Yokota et al. [55] regarding four different body forms (A: tall-fat, B: tall-lean, C: short-lean, D: short-fat). It can be seen that the results of the ITB model are in good agreement with the mentioned results. The results of the ITB model are accurately followed the trend of core temperature graphs for all subjects (A, B, C, D). In Table 7, the mean absolute errors and maximum errors of the present model are compared with the results that simulated by Gagge model. In addition, the mean absolute errors are determined as $0.16,0.11$, 0.18 , and 0.15 for $\mathrm{A}, \mathrm{B}, \mathrm{C}$ and $\mathrm{D}$, while these mean absolute errors are reduced in compare with Gagge model, 27\%, 21\%, 14\% and 31\% respectively. A pair samples $t$-test was conducted to determine how effective the ITB model was at reducing mean absolute errors. There was a significant difference in mean absolute errors for Gagge model $(\mathrm{M}=0.20, \mathrm{SD}=0.04)$ and ITB model $(\mathrm{M}=0.15, \mathrm{SD}=0.02)$ simulations; $t(3)=4.08, p=0.02$. Specifically, our results suggest that the present model can predict the core body temperature more accurate.

(1)

(1)
19
20

21 (1)

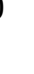
1 


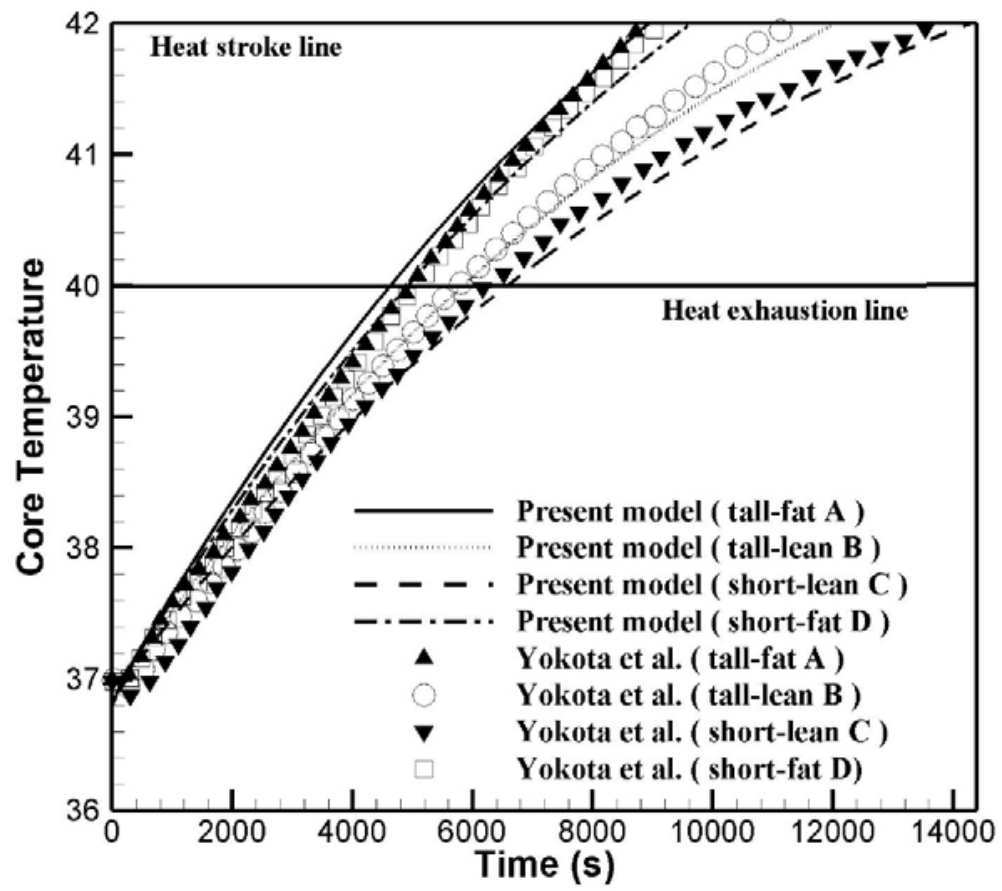

Fig. 15 Comparison of the core temperature [55] results with simulated by the present model among four different body forms (A: tall-fat, B: tall-lean, C: short-lean, D: short-fat).

5 Table 7 Mean absolute errors (MAE) and maximum errors between measurement data and 6 simulated results from the present model and Gagge's model for core temperature $\left(T_{\mathrm{cr}}\right)$.

\begin{tabular}{lccccc} 
& \multicolumn{2}{c}{$\begin{array}{c}\text { Mean Absolute Error } \\
(\mathrm{MAE})\left({ }^{\circ} \mathrm{C}\right)\end{array}$} & \multicolumn{2}{c}{$\begin{array}{c}\text { Maximum Error } \\
\left({ }^{\circ} \mathrm{C}\right)\end{array}$} & $\begin{array}{c}\text { Change in Error } \\
(\%)\end{array}$ \\
\cline { 2 - 6 } $\begin{array}{l}\text { Subject } \\
\text { Groups }\end{array}$ & $\begin{array}{c}\text { Gagge } \\
\text { Model }\end{array}$ & $\begin{array}{c}\text { Present } \\
\text { Model }\end{array}$ & $\begin{array}{c}\text { Gagge } \\
\text { Model }\end{array}$ & $\begin{array}{c}\text { Present } \\
\text { Model }\end{array}$ & $\begin{array}{l}\left(\mathrm{MAE}_{\text {Gagge }}-\mathrm{MAE}_{\text {Present }}\right) \\
\text { A }\end{array}$ \\
\hline A & 0.22 & 0.16 & 0.20 & 0.18 & 27 \\
B & 0.14 & 0.11 & 0.19 & 0.16 & 21 \\
$\mathrm{C}$ & 0.21 & 0.18 & 0.24 & 0.21 & 14 \\
$\mathrm{D}$ & 0.23 & 0.15 & 0.20 & 0.17 & 34 \\
\hline
\end{tabular}


1 As another test case, the results of the new ITB model, Gagge's 2-node model, the STB model, and the measured data of Lichtenbelt et al. [56] were compared. In Table 8, the personal factors of participants in the experiment of Lichtenbelt et al. [56] are presented. The experiment schedule of Lichtenbelt et al. [56] is shown in Fig. 16. In the mentioned experiment, the subjects were exposed to a mildly cold environment $\left(15^{\circ} \mathrm{C}\right)$ for 3 hours. Fig. 17 compares the mean skin temperature obtained from the ITB model with the results of the STB model [38], Gagge's model [6] and the empirical data of Lichtenbelt et al. [56]. It should be mentioned that the participants in the study of Lichtenbelt et al. [56] had two obvious differences with the subjects considered in standard population-based models: they had lower body weights, and they were all female. Previous empirical studies have reported that the skin temperature of obese subjects shows a slower reaction to cold exposure conditions than lean ones [57-59]. Moreover, many studies have revealed that the skin temperature of females is usually lower than that of males, and females are more sensitive to warm and cold thermal conditions $[60,61]$. These results are in conformity with previously published data. On the other hand, in Table 9 mean absolute errors and mean absolute percentage error between measurement data and simulated results from the present model, STB model and Gagge's model have been compared. As can be seen, in this case, mean absolute errors can be reduced $38 \%$ and $31 \%$ which simulation has been done by ITB model instead of Gagge madel and STB model respectively. Therefore, predictions from ITB model are superior to Gagge model and STB model in this case.

Table 8 Individual characteristics of volunteers that participated in the experiment of Lichtenbelt et al. [56] for 10 female and 10 male.

\begin{tabular}{lccc}
\hline Female $(\mathrm{n}=10)$ and Male $(\mathrm{n}=10)$ & Mean \pm SD & Min & Max \\
\hline Age (years) & 30 & 19 & 36 \\
Weight $(\mathrm{kg})$ & $71.1 \pm 14.4$ & 51.2 & 107.2 \\
Height (m) & $1.74 \pm 0.09$ & 1.55 & 1.85 \\
Body fat (\%) & $22.5 \pm 8.4$ & 8.2 & 36 \\
\hline
\end{tabular}




\begin{tabular}{|c|c|c|}
\hline Velocity & $0.1 \mathrm{~m} / \mathrm{s}$ & $0.1 \mathrm{~m} / \mathrm{s}$ \\
\hline RH & $50 \%$ & $50 \%$ \\
\hline Air temp. & $22^{\circ} \mathrm{C}$ & $15^{\circ} \mathrm{C}$ \\
\hline Condition & Neutral & Cold \\
\hline Level & Phase I & Phase II \\
\hline Time & & \\
\hline
\end{tabular}

Fig. 16 Schedule and conditions of Lichtenbelt et al. [56] experiment.

1

2

3

4

5

6

7

9

10

11

12

13

14

15

16

17

18

19

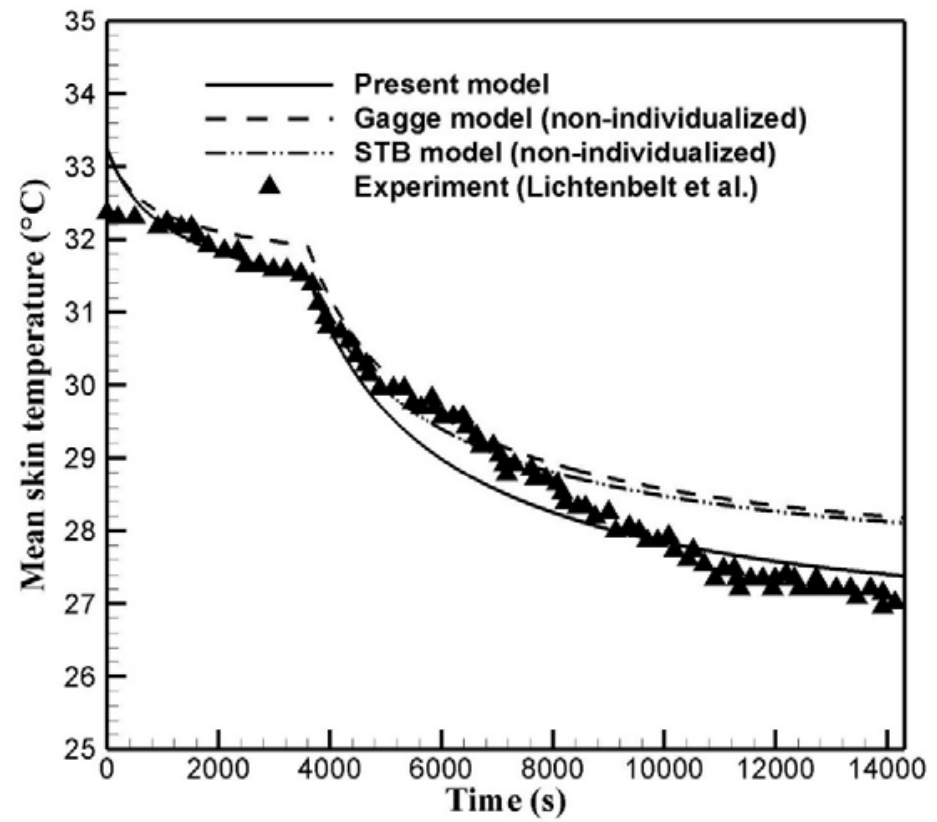

Fig. 17 Comparison of the measured and simulated mean skin temperatures [56] using Gagge's model, STB model and the present model. 
Table 9 Mean absolute errors (MAE) and mean absolute percentage error (MAPE) between measurement data and simulated results from the present model, STB model and Gagge's model for mean skin temperature $\left(T_{\text {sk,mean }}\right)$.

\begin{tabular}{cccccccc}
\hline \multicolumn{2}{c}{$\begin{array}{c}\text { Mean Absolute Error } \\
(\mathrm{MAE})\left({ }^{\circ} \mathrm{C}\right)\end{array}$} & \multicolumn{2}{c}{$\begin{array}{c}\text { Mean Absolute Percentage } \\
\text { Error (MAPE) }(\%)\end{array}$} & \multicolumn{2}{c}{$\begin{array}{c}\text { Change in Error } \\
(\%)\end{array}$} \\
\hline $\begin{array}{c}\text { Gagge } \\
\text { Model }\end{array}$ & $\begin{array}{c}\text { STB } \\
\text { Model }\end{array}$ & $\begin{array}{c}\text { Present } \\
\text { Model }\end{array}$ & $\begin{array}{c}\text { Gagge } \\
\text { Model }\end{array}$ & $\begin{array}{c}\text { STB } \\
\text { Model }\end{array}$ & $\begin{array}{c}\text { Present } \\
\text { Model }\end{array}$ & $\begin{array}{c}\text { ITB model } \\
\text { instead } \\
\text { Gagge model }\end{array}$ & $\begin{array}{c}\text { ITB model } \\
\text { instead } \\
\text { STB model }\end{array}$ \\
\hline 0.40 & 0.36 & 0.24 & 1.42 & 1.26 & 0.84 & 38 & 31 \\
\hline
\end{tabular}

To observe the capability of the ITB model to predict the body thermoregulatory responses for different genders, the empirical results of Fournet et al. [62] were applied. In the mentioned experiment, 8 males and 8 females took part in a laboratory-simulated hike for 110 minutes under the conditions shown in Fig. 18. The experiment schedule was divided into four main stages: standing rest (Preparation), ascent (Climb), seated rest (Summit), and descent (Downhill walking). The participants' clothing insulation was estimated to be $\approx 0.26$ clo (T-shirts, fleece tops, and trousers) and they carried a backpack ( $10 \%$ body mass) during a simulated hike in a $15{ }^{\circ} \mathrm{C}$ environment.

In Table 10, the results of the ITB model and Gagge model for mean skin temperature are compared with the empirical data from the study of Fournet et al. [62]. As can be seen, the ITB model can predict mean skin temperature for both males and females by considering individual parameters with very good accuracy. In all four main stages, the results revealed that females have a lower mean skin temperature than males under cold environmental conditions. The maximum and minimum of mean absolute errors for the ITB model simulated mean skin temperature and the experimental results were $0.24^{\circ} \mathrm{C}$ (female - climb stage) and $0.06^{\circ} \mathrm{C}$ (male - preparation stage), respectively. A paired-samples $t$-test was conducted to compare mean absolute error that obtained from Gagge model and ITB model for the conditions of this dataset. Results indicated that mean absolute errors of ITB model $(M=0.14, S D=0.06)$ were significantly lower than the mean absolute errors for the Gagge model $(M=0.49, S D=0.37)$ as a standard model $(t(7)=2.91, p<$ 
10.05 ), indicating that predictions from the ITB model are more accurate in comparison with Gagge

2 model in these datasets.

3

4

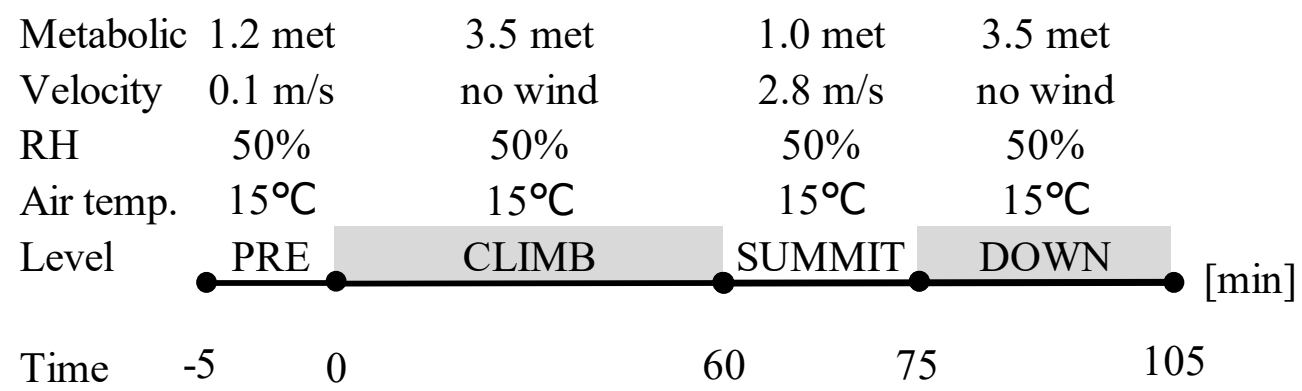

Fig. 18 Experiment schedule and conditions in the study of Fournet et al. [62].

9 Table 10 Comparison of the measured [62] and simulated mean skin temperatures (male $=8$, 10 female $=8$ ) and mean absolute errors.

\begin{tabular}{|c|c|c|c|c|c|c|}
\hline \multirow{3}{*}{ Phase } & \multirow{3}{*}{ Gender } & \multicolumn{3}{|c|}{ Mean skin Temperature $\left({ }^{\circ} \mathrm{C}\right)$} & \multicolumn{2}{|c|}{ Mean Absolute Error $\left({ }^{\circ} \mathrm{C}\right)$} \\
\hline & & Experiment & Gagge & Present & Gagge & Present \\
\hline & & & Model & Model & Model & Model \\
\hline \multirow{2}{*}{$\begin{array}{l}\text { Preparation } \\
(1.2 \mathrm{met})\end{array}$} & Male & 28.58 & 28.73 & 28.64 & 0.15 & 0.06 \\
\hline & Female & 28.18 & 28.73 & 28.33 & 0.55 & 0.15 \\
\hline \multirow{2}{*}{$\begin{array}{l}\text { Climb } \\
\text { (3.5 met) }\end{array}$} & Male & 28.88 & 29.13 & 29.01 & 0.25 & 0.13 \\
\hline & Female & 27.96 & 29.13 & 28.20 & 1.17 & 0.24 \\
\hline Summit & Male & 28.71 & 28.87 & 28.82 & 0.16 & 0.11 \\
\hline
\end{tabular}




$\begin{array}{llllccc}(1.0 \mathrm{met}) & \text { Female } & 27.94 & 28.87 & 28.12 & 0.93 & 0.18 \\ \text { Down } & \text { Male } & 29.55 & 29.86 & 29.78 & 0.31 & 0.23 \\ (3.5 \mathrm{met}) & \text { Female } & 29.45 & 29.86 & 29.52 & 0.41 & 0.07\end{array}$

1

2

To validate the results obtained from the new individualized model for both the elderly and young adults, the differences in mean skin temperature between the new model and the measured data were compared in 7 different cases [63-65]. The subjects' characteristics and the environmental conditions for all 7 experimental cases are presented in Table 11. Table 12 shows the absolute mean temperature differences between measured data and the standard Gagge's model, and the individualized model results for mean skin temperature are also shown. The results indicate that the new ITB model can predict mean skin temperature with a good accuracy. Moreover, previous studies have reported that elderly people have a generally higher core temperature and lower mean skin temperature under warm exposure. Conversely, elderly people have a lower core temperature and higher mean skin temperature when exposed to cold ambient temperatures in comparison with young adults $[30,66]$. These mentioned points were also confirmed by the results obtained with the present model. It should be noted that the elderly cannot reduce heat loss in low temperatures as rapidly as young adults can; nor can they increase heat loss in high temperatures with the thermoregulatory system as rapidly as young people (active system) [67]. As seen in Table 12, the standard Gagge's model predicts the same value of mean skin temperature for both the elderly and young adults. Moreover, the new ITB model can accurately predict mean skin temperature for the elderly and young adults, and there is good agreement with published experimental results. Obviously, the symptom of this good agreement is clarified in Table 12 where the mean skin temperature that estimated by the ITB model (as individualized model) is closer to measured data in comparison with the results of Gagge's model (as non-individual model). This improvement is mentioned in Table 12 as change in error (between 14\% to $42 \%$ for different cases). T-test confirmed that for these datasets the ITB model's mean absolute errors is reduced compared to the Gagge model $(t(11)=5.67, p<0.001)$. 
1 Table 11 Summary of subjects' individual characteristics and environmental conditions in 7

2 different experimental cases.

\begin{tabular}{lccc}
\hline Reference & $\begin{array}{l}\text { Case A,B\&C } \\
\text { (Tsuzuki and Ohfuku, } \\
\text { 2002)[64] }\end{array}$ & $\begin{array}{c}\text { Case D \& E } \\
\text { (Inoue et al., } \\
\text { 1992) [63] }\end{array}$ & $\begin{array}{l}\text { Case F \&G } \\
\text { (Ting Ma et al., } \\
2017)[65]\end{array}$ \\
\hline $\begin{array}{l}\text { Sample size } \\
\text { (Elderly /Young Adult) }\end{array}$ & $\begin{array}{c}2009 \\
(109 / 100)\end{array}$ & $\begin{array}{c}(19 / 9) \\
(5 / 0)\end{array}$ & 1.0 \\
Activity Level (met) & 1.3 & 1.0 & 1.2 \\
Clothing (clo) & 0.63 & 0.06 & 30 \\
Relative humidity (\%) & 60 & 45 & 0.05 \\
Air velocity (m/s) & $\leq 0.2$ & 0.1 & $\mathrm{~F}=19 \& \mathrm{G}=21$ \\
Air temperature $\left({ }^{\circ} \mathrm{C}\right)$ & $\mathrm{A}=23, \mathrm{~B}=27 \& \mathrm{C}=31$ & $\mathrm{D}=12 \& \mathrm{E}=17$ & \\
\hline
\end{tabular}

3

4

5

6

7 Table 12 Mean absolute temperature differences between the results of the new individual model

8 and measured data for mean skin temperature $\left(T_{s k, m e a n}\right)$.

\begin{tabular}{|c|c|c|c|c|}
\hline \multirow{4}{*}{ Case } & \multirow{4}{*}{ Age Range } & \multicolumn{2}{|c|}{$\begin{array}{c}\text { Mean absolute temperature } \\
\text { difference }\left({ }^{\circ} \mathrm{C}\right)\end{array}$} & \multirow{3}{*}{$\begin{array}{c}\text { Change in Error (\%) } \\
\frac{\left(\mathrm{MAE}_{\text {Gagge }}-\mathrm{MAE}_{\text {Present }}\right)}{\mathrm{MAE}_{\text {Gagoe }}}\end{array}$} \\
\hline & & Standard & Individualized & \\
\hline & & Model & model & \\
\hline & & (Gagge Model) & (Present Model) & $\times 100$ \\
\hline \multirow[t]{2}{*}{ A } & Elderly & 0.38 & 0.22 & 42 \\
\hline & Young Adult & 0.24 & 0.15 & 37 \\
\hline \multirow[t]{2}{*}{ B } & Elderly & 0.14 & 0.11 & 21 \\
\hline & Young Adult & 0.12 & 0.10 & 16 \\
\hline $\mathrm{C}$ & Elderly & 0.46 & 0.28 & 39 \\
\hline
\end{tabular}




\begin{tabular}{lllll} 
& Young Adult & 0.32 & 0.21 & 34 \\
D & Elderly & 0.56 & 0.33 & 41 \\
& Young Adult & 0.21 & 0.18 & 14 \\
E & Elderly & 0.48 & 0.30 & 37 \\
& Young Adult & 0.18 & 0.11 & 38 \\
F & Elderly & 0.37 & 0.26 & 29 \\
G & Elderly & 0.34 & 0.23 & 32 \\
\hline
\end{tabular}

\section{Conclusion}

In this study, a new individualized thermoregulatory bio-heat model was developed based on the STB model to predict the time-dependent temperature distribution in living tissue layers and to evaluate thermal responses of the human body to environmental conditions. The STB model was established by utilizing Pennes' equation and Gagge's standard 2-node model, and it was capable of accurately estimating the temperature and its time derivative at the depth of the cutaneous thermoreceptors. It should be noted that individual parameters, such as anthropometric characteristics, age, gender, and basal metabolic rate, play significant roles in human body thermoregulation. The present individual model tried to utilize personal factors in the model structure. Subsequently, it was validated against the published empirical data, with which a good agreement was achieved. In conclusion, the results illustrate that the present model can estimate the thermal responses of cutaneous thermoreceptors under various steady/transient conditions individually and with very good accuracy. The present model is able to make a reasonably accurate prediction of individuals' thermoregulatory responses. Also, the results of this model can be utilized to estimate each individuals' thermal sensation level. Future research should focus more on introducing a new predictive index for evaluating individual thermal sensation and thermal response of the body (i.e., similar to what was done by Zolfaghari and Maerefat [39]). The mentioned index can be helpful for engineers to design personalize ventilation systems and even design of building for various subjects, such as children, men, women, the elderly, patients, etc. Moreover, the model can be used for better understanding the comfort needs of occupants. It also can be utilized to design and control optimal conditioning besides improving satisfaction for spaces like vehicle, aircraft, and personal comfort system. 


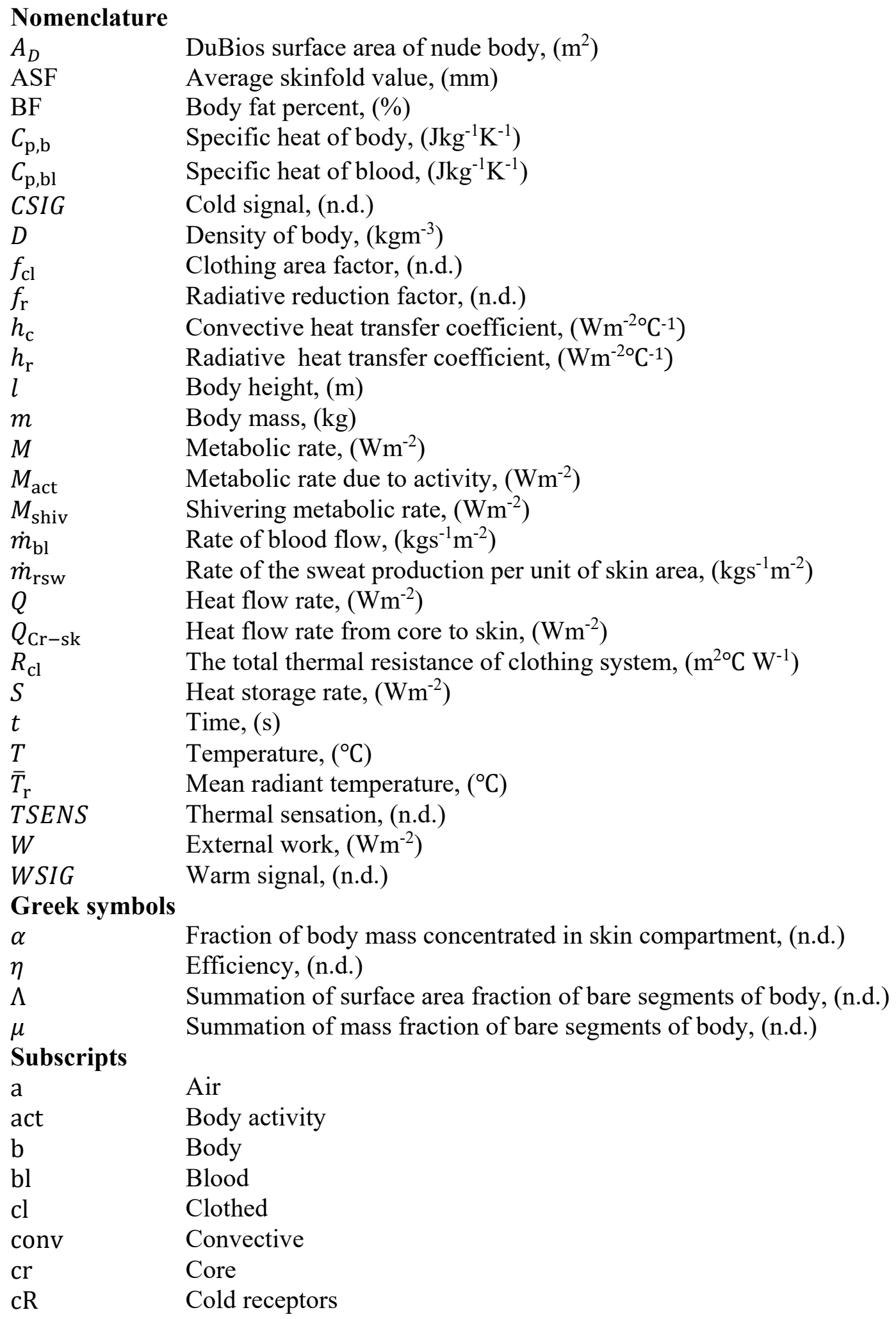




$\begin{array}{ll}\text { evap } & \text { Evaporative } \\ \mathrm{F} & \text { Female } \\ \mathrm{M} & \text { Male } \\ \mathrm{n} & \text { Neutral } \\ \text { ov } & \text { Overall } \\ \text { rad } & \text { Radiation } \\ \text { res } & \text { Respiration } \\ \text { sk } & \text { Skin } \\ \text { wR } & \text { Warm receptor }\end{array}$

\section{References:}

[1] A. Bhowmik, R. Singh, R. Repaka, S.C. Mishra, Conventional and newly developed bioheat transport models in vascularized tissues: A review, Journal of Thermal Biology 38(3) (2013) 107-125.

[2] K. Katić, R. Li, W. Zeiler, Thermophysiological models and their applications: A review, Building and Environment 106 (2016) 286-300.

[3] P.O. Fanger, Thermal comfort analysis and applications in environmental engineering, McGraw-Hill, New York, 1970.

[4] ASHRAE, ASHRAE handbook of fundamentals, ASHRAE, Atlanta, 2001.

[5] ISO7730, Moderate thermal environments-Determination of the PMV and PPD indices and specification of the conditions for thermal comfort, International Standards Organization1994.

[6] A.P. Gagge, J.A.J. Stolwijk, Y. Nishi, An effective temperature scale based on a simple model of human physiological regulatory response, ASHRAE Transactions 77(1) (1971) 247-262.

[7] A. Zolfaghari, M. Maerefat, A new simplified model for evaluating non-uniform thermal sensation caused by wearing clothing, Building and Environment 45(3) (2010) 776-783.

[8] J.A.J. Stolwijk, A mathematical model of physiological temperature regulation in man, NASA contractor report, NASA CR-1855, National Aeronautics and Space Administration, Washington D.C., 1971.

[9] C. Huizenga, Z. Hui, E. Arens, A model of human physiology and comfort for assessing complex thermal environments, Building and Environment 36(6) (2001) 691-699.

[10] S.-i. Tanabe, K. Kobayashi, J. Nakano, Y. Ozeki, M. Konishi, Evaluation of thermal comfort using combined multi-node thermoregulation $(65 \mathrm{MN})$ and radiation models and computational fluid dynamics (CFD), Energy and Buildings 34 (2002) 637-646.

[11] L. Schellen, M.G.L.C. Loomans, B.R.M. Kingma, M.H. de Wit, A.J.H. Frijns, W.D. van Marken Lichtenbelt, The use of a thermophysiological model in the built environment to predict thermal sensation: Coupling with the indoor environment and thermal sensation, Building and Environment 59 (2013) 10-22.

[12] O. Kaynakli, M. Kilic, Investigation of indoor thermal comfort under transient conditions, Building and Environment 40(2) (2005) 165-174.

[13] D. Fiala, L. K.J., M. Stohrer, Computer prediction of human thermoregulatory and temperature responses to a wide range of environmental conditions, International Journal of Biometeorology 45 (2001) 143-159.

[14] D. Fiala, G. Havenith, Modelling Human Heat Transfer and Temperature Regulation, in: A. Gefen, Y. Epstein (Eds.), The Mechanobiology and Mechanophysiology of Military-Related Injuries, Springer International Publishing, Cham, 2016, pp. 265-302.

[15] A.M.J. van Ooijen, W.D. van Marken Lichtenbelt, K.R. Westerterp, Individual differences in body temperature and the relation to energy expenditure: the influence of mild cold, Journal of Thermal Biology 26(4-5) (2001) 455-459. 
[16] G. Havenith, Individual heat stress response, Medische wetenschappen: Nijmegen: 1997., 1997.

[17] G. Havenith, Individualized model of human thermoregulation for the simulation of heat stress response, Journal of Applied Physiology 90 (2001) 1943-1954.

[18] W.A. Lotens, Heat Transfer from Humans Wearing Clothing, Delft Univ. of Technology, Delft, The Netherlands, 1993.

[19] H. Zhang, C. Huizenga, E. Arens, T. Yu, Considering individual physiological differences in a human thermal model, Journal of Thermal Biology 26(4-5) (2001) 401-408.

[20] W.D. Van Marken Lichtenbelt, A.J.H. Frijns, D. Fiala, F.E.M. Janssen, A.M.J. Van Ooijen, A.A. Van Steenhoven, Effect of individual characteristics on a mathematical model of human thermoregulation, Journal of Thermal Biology 29 (2004) 577-581.

[21] S. Karjalainen, Gender differences in thermal comfort and use of thermostats in everyday thermal environments, Building and Environment 42(4) (2007) 1594-1603.

[22] S. Karjalainen, Thermal comfort and gender: a literature review, Indoor Air 22(2) (2012) 96-109.

[23] R. Holopainen, A human thermal model for improved thermal comfort, VTT Technical Research Centre of Finland2012.

[24] R. Holopainen, P. Tuomaala, P. Hernandez, T. Häkkinen, K. Piira, J. Piippo, Comfort assessment in the context of sustainable buildings: Comparison of simplified and detailed human thermal sensation methods, Building and Environment 71 (2014) 60-70.

[25] X. Zhou, Z. Lian, L. Lan, An individualized human thermoregulation model for Chinese adults, Building and Environment 70(0) (2013) 257-265.

[26] J.-H. Choi, D. Yeom, Study of data-driven thermal sensation prediction model as a function of local body skin temperatures in a built environment, Building and Environment 121 (2017) 130-147.

[27] J. Kim, Y. Zhou, S. Schiavon, P. Raftery, G. Brager, Personal comfort models: Predicting individuals' thermal preference using occupant heating and cooling behavior and machine learning, Building and Environment 129 (2018) 96-106.

[28] J. Kim, S. Schiavon, G. Brager, Personal comfort models - A new paradigm in thermal comfort for occupant-centric environmental control, Building and Environment (2018), in press.

[29] T. Chaudhuri, D. Zhai, Y.C. Soh, H. Li, L. Xie, Thermal comfort prediction using normalized skin temperature in a uniform built environment, Energy and Buildings 159 (2018) 426-440.

[30] F. Davoodi, H. Hasanzadeh, S. Alireza Zolfaghari, M. Maerefat, Developing a new individualized 3node model for evaluating the effects of personal factors on thermal sensation, Journal of Thermal Biology 69 (2017) 1-12.

[31] H. Hensel, Thermoreception and temperature regulation, Academic Press, London, 1981.

[32] J.W. Ring, R. de Dear, Temperature Transients: A Model for Heat Diffusion through the Skin, Thermoreceptor Response and Thermal Sensation, Indoor Air 1(4) (1991) 448-456.

[33] J.W. Ring, R. de Dear, A. Melikov, Human thermal sensation: frequency response to sinusoidal stimuli at the surface of the skin, Energy and Buildings 20(2) (1993) 159-165.

[34] Y.-G. Lv, J. Liu, Interpretation on thermal comfort mechanisms of human bodies by combining Hodgkin-Huxley neuron model and Pennes bioheat equation, Forschung im Ingenieurwesen 69 (2005) 101-114.

[35] Y.-G. Lv, J. Liu, Effect of transient temperature on thermoreceptor response and thermal sensation, Building and Environment 42(2) (2007) 656-664.

[36] H.H. Pennes, Analysis of Tissue and Arterial Blood Temperatures in the Resting Human Forearm, J Appl Physiol 1(2) (1948) 93-122.

[37] E.H. Wissler, Pennes' 1948 paper revisited, Journal of applied physiology (Bethesda, Md. : 1985) 85(1) (1998) 35-41. 
[38] A. Zolfaghari, M. Maerefat, A new simplified thermoregulatory bioheat model for evaluating thermal response of the human body to transient environments, Building and Environment 45(10) (2010) 20682076.

[39] A. Zolfaghari, M. Maerefat, A new predictive index for evaluating both thermal sensation and thermal response of the human body, Building and Environment 46(4) (2011) 855-862.

[40] A. Yigit, Combining thermal comfort models, ASHRAE Transactions 105(1) (1999) 149-158.

[41] K. Katić, R. Li, B. Kingma, W. Zeiler, Modelling hand skin temperature in relation to body composition, Journal of Thermal Biology 69(Supplement C) (2017) 139-148.

[42] D. Du Bois, E.F. Du Bois, A formula to estimate the approximate surface area if height and weight be known. 1916, Nutrition (Burbank, Los Angeles County, Calif.) 5(5) (1989) 303-11; discussion 312-3.

[43] X. Wang, K.T. högskolan, Thermal Comfort and Sensation Under Transient Conditions, Department of Energy Technology, Division of Heating and Ventilation, the Royal Institute of Technology1994.

[44] G. Eknoyan, Adolphe Quetelet (1796-1874)--the average man and indices of obesity, Nephrology, dialysis, transplantation : official publication of the European Dialysis and Transplant Association European Renal Association 23(1) (2008) 47-51.

[45] D. Fiala, G. Havenith, Modelling Human Heat Transfer and Temperature Regulation, in: A. Gefen, Y. Epstein (Eds.), The Mechanobiology and Mechanophysiology of Military-Related Injuries, Springer International Publishing, Cham, 2016, pp. 265-302.

[46] D.A. Santos, J.A. Dawson, C.N. Matias, P.M. Rocha, C.S. Minderico, D.B. Allison, L.B. Sardinha, A.M. Silva, Reference Values for Body Composition and Anthropometric Measurements in Athletes, PLoS ONE 9(5) (2014) e97846.

[47] B. Li, Y. Yang, R. Yao, H. Liu, Y. Li, A simplified thermoregulation model of the human body in warm conditions, Applied Ergonomics 59, Part A (2017) 387-400.

[48] E.A. Arens, H. Zhang, The skin's role in human thermoregulation and comfort, 2006.

[49] G. Havenith, D. Fiala, Thermal Indices and Thermophysiological Modeling for Heat Stress, Comprehensive Physiology, John Wiley \& Sons, Inc.2011.

[50] B. Kingma, Human thermoregulation: a synergy between physiology and mathematical modelling, Universitaire Pers2012.

[51] B.R.M. Kingma, M. Schweiker, A. Wagner, W.D. van Marken Lichtenbelt, Exploring internal body heat balance to understand thermal sensation, Building Research \& Information (2017) 1-11.

[52] WHO, Human energy requirements: report of a joint FAO/ WHO/UNU Expert Consultation, Food and nutrition bulletin 26(1) (2005) 166.

[53] H.-Y. Liu, Y.-F. Lu, W.-J. Chen, Predictive Equations for Basal Metabolic Rate in Chinese Adults, Journal of the Academy of Nutrition and Dietetics 95(12) 1403-1408.

[54] Y. Yang, R. Yao, B. Li, H. Liu, L. Jiang, A method of evaluating the accuracy of human body thermoregulation models, Building and Environment 87 (2015) 1-9.

[55] M. Yokota, L.G. Berglund, G.P. Bathalon, Monte Carlo simulations of individual variability and their effects on simulated heat stress using thermoregulatory modeling, Journal of Thermal Biology 35(3) (2010) 154-159.

[56] W.D. Van Marken Lichtenbelt, A.J.H. Frijns, A.M.J. Van Ooijen, D. Fiala, A.M. Kester, A.A. Van Steenhoven, Validation of an individualizred model of human thermoregulation for predicting responses to cold air, International Journal of Biometeorology 51 (2007) 169-179.

[57] A.M. Claessens-van Ooijen, K.R. Westerterp, L. Wouters, P.F. Schoffelen, A.A. van Steenhoven, W.D. van Marken Lichtenbelt, Heat production and body temperature during cooling and rewarming in overweight and lean men, Obesity (Silver Spring, Md.) 14(11) (2006) 1914-20.

[58] M. Chudecka, A. Lubkowska, A. Kempińska-Podhorodecka, Body surface temperature distribution in relation to body composition in obese women, Journal of Thermal Biology 43(Supplement C) (2014) 1-6. 
[59] M.E. Hoffmann, S.M. Rodriguez, D.M. Zeiss, K.N. Wachsberg, R.F. Kushner, L. Landsberg, R.A. Linsenmeier, 24-h core temperature in obese and lean men and women, Obesity (Silver Spring, Md.) 20(8) (2012) 1585-90.

[60] L. Lan, Z. Lian, W. Liu, Y. Liu, Investigation of gender difference in thermal comfort for Chinese people, Eur J Appl Physiol 102(4) (2008) 471-80.

[61] Y. Inoue, N. Gerrett, T. Ichinose-Kuwahara, Y. Umino, S. Kiuchi, T. Amano, H. Ueda, G. Havenith, N. Kondo, Sex differences in age-related changes on peripheral warm and cold innocuous thermal sensitivity, Physiol Behav 164(Pt A) (2016) 86-92.

[62] D. Fournet, K.E. Griggs, B. Redortier, G. Havenith, Sex differences in thermal strain induced by a typical hiking scenario in a cool environment, (2013).

[63] Y. Inoue, M. Nakao, T. Araki, H. Ueda, Thermoregulatory responses of young and older men to cold exposure, Eur J Appl Physiol Occup Physiol 65(6) (1992) 492-8.

[64] K. Tsuzuki, T. Ohfuku, Thermal sensation and thermoregulation in elderly compared to young people in Japanese winter season, Proceedings of indoor air 2 (2002) 659-664.

[65] T. Ma, J. Xiong, Z. Lian, A human thermoregulation model for the Chinese elderly, Journal of Thermal Biology (2017).

[66] M. Rida, N. Ghaddar, K. Ghali, J. Hoballah, Elderly bioheat modeling: changes in physiology, thermoregulation, and blood flow circulation, International journal of biometeorology 58(9) (2014) 18251843.

[67] Y. Tochihara, T. Ohnaka, Y. Nagai, T. Tokuda, Y. Kawashima, Physiological responses and thermal sensations of the elderly in cold and hot environments, Journal of Thermal Biology 18(5) (1993) 355-361. 